\title{
Borneo vortex and mesoscale convective rainfall
}

\author{
S. Koseki ${ }^{1}$, T.-Y. Koh ${ }^{2,3}$, and C.-K. Teo ${ }^{2}$ \\ ${ }^{1}$ Temasek Laboratories, Nanyang Technological University, Singapore \\ ${ }^{2}$ School of Physical and Mathematical Science, Nanyang Technological University, Singapore \\ ${ }^{3}$ Earth Observatory of Singapore, Nanyang Technological University, Singapore \\ Correspondence to: T.-Y. Koh (kohty@ntu.edu.sg)
}

Received: 28 May 2013 - Published in Atmos. Chem. Phys. Discuss.: 13 August 2013

Revised: 10 March 2014 - Accepted: 22 March 2014 - Published: 9 May 2014

\begin{abstract}
We have investigated how the Borneo vortex develops over the equatorial South China Sea under cold surge conditions in December during the Asian winter monsoon. Composite analysis using reanalysis and satellite data sets has revealed that absolute vorticity and water vapour are transported by strong cold surges from upstream of the South China Sea to around the Equator. Rainfall is correspondingly enhanced over the equatorial South China Sea. A semi-idealized experiment reproduced the Borneo vortex over the equatorial South China Sea during a "perpetual" cold surge. The Borneo vortex is manifested as a meso$\alpha$ cyclone with a comma-shaped rainband in the northeast sector of the cyclone. Vorticity budget analysis showed that the growth/maintenance of the meso- $\alpha$ cyclone was achieved mainly by the vortex stretching. This vortex stretching is due to the upward motion forced by the latent heat release around the cyclone centre. The comma-shaped rainband consists of clusters of meso- $\beta$-scale rainfall cells. The intense rainfall in the comma head (comma tail) is generated by the confluence of the warmer and wetter cyclonic easterly flow (cyclonic southeasterly flow) and the cooler and drier northeasterly surge in the northwestern (northeastern) sector of the cyclone. Intense upward motion and heavy rainfall resulted due to the low-level convergence and the favourable thermodynamic profile at the confluence zone. In particular, the convergence in the northwestern sector is responsible for maintenance of the meso- $\alpha$ cyclone system. At both meso- $\alpha$ and meso- $\beta$ scales, the convergence is ultimately caused by the deviatoric strain in the confluence wind pattern but is significantly self-enhanced by the nonlinear dynamics.
\end{abstract}

\section{Introduction}

Activity of the Asian monsoon is related to the seasonal migration of the Intertropical Convergence Zone (ITCZ; e.g. Hubert et al., 1969) and plays a key role in the climate and weather systems in the Maritime Continent. Basically, the Asian winter monsoon is forced by land-sea thermal contrast between the cool Eurasian continent (high surface pressure) and the warm sea surface in East and Southeast Asia (low surface pressure) in boreal winter (e.g. Tomita and Yasunari 1996). Northeasterly winds prevail over the South China Sea (Fig. 1a) in the lower troposphere. This northeasterly monsoonal flow is cool and dry because the air mass originates from the Eurasian landmass and the monsoon enhances upward sensible and latent heat fluxes over the South China Sea. The enhanced surface fluxes contribute partly to the generation of the cold tongue in sea surface temperature (SST) (Chen et al., 2003) in the South China Sea during the winter monsoonal season.

Occasionally, the low-level northeasterly winds from the Eurasian continent associated with the Asian winter monsoon can abruptly intensify. Such rapid intensification of the Asian winter monsoon which is related to the activity of the Siberian High (e.g. Joung and Hitchman, 1982; Takaya and Nakamura, 2005) is commonly known as a cold air outbreak or cold surge (although by the time it reaches the Maritime continent, the air temperature has warmed up considerably due to sensible heat fluxes from the underlying South China Sea). In the mid-latitudes, the cold surge forces the Japan Sea Polar Airmass Convergence Zone (JPCZ; e.g. Asai, 1988) and induces cumulus convection over the Sea of Japan which subsequently brings heavy snowfall around coastal northern Japan (Nagata, 1987, 1993; Tsuboki 


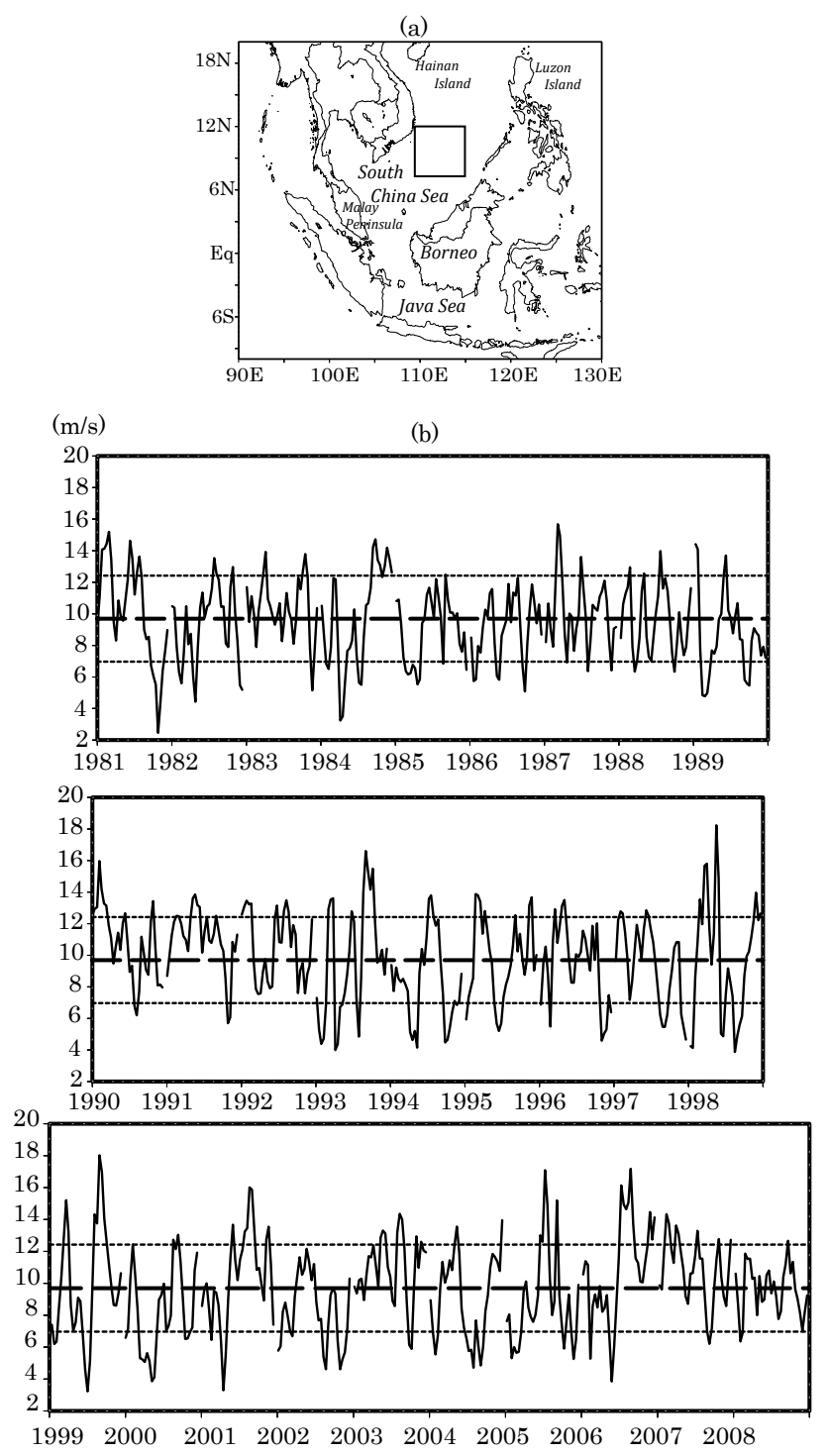

Fig. 1. (a) The geography of the Maritime continent. The black box denotes the area for Cold Surge (CS) Index. (b) CS Index obtained from daily JRA25/JCDAS in December from 1981 to 2008. The thick dashed line is the climatology of the CS Index and thin dotted lines are the climatology \pm 1 standard deviation of CS Index. CS Index is defined as area-averaged wind speed at $850 \mathrm{hPa}$ over 7.5 to $12.5^{\circ} \mathrm{N}$ and 110 to $115^{\circ} \mathrm{E}$. The lines are disjoint between years.

and Asai, 2004; Kawashima and Fujiyoshi, 2005). The cold surge induces a sudden depression in temperature and an increase in the sea surface pressure in the coastal sea off southern China (e.g. Hong et al., 2009; Lu and Chang, 2009). In the Southeast Asia region, the cold surge persists for a few days to about 1 week over the South China Sea and causes severe hazards such as heavy rainfall and flooding (e.g. Wangwongchai et al., 2005; Tangang et al., 2008; Hattori et al., 2011; Trilaksono et al., 2012). The northeasterly winds can trigger convection through interaction with the local sea/land breeze circulation (e.g. Estoque, 1962) and through the topography lifting effect (e.g. Seko et al., 2008).

Moreover, cold surges in the Maritime continent often spin up meso- $\alpha$-scale cyclonic circulation known as Borneo vortices (e.g. Chen et al., 1986; Lau and Chang, 1987; Johnson and Houze, 1987; Juneng and Tangang, 2010; Braesicke et al., 2012) near the Borneo Island. Chang et al. (2005) studied the variability in the Borneo vortex and cold surge using satellite observational and reanalysis data sets. They concluded that deep cumulus convection tends to occur frequently over the South China Sea in the presence of Borneo vortices. A Borneo vortex generally has a shallow vertical structure, but in the extreme case, it could intensify into a tropical storm, and in one instance, even a typhoon with a deep vortex tube and a well-formed eyewall despite its proximity to the Equator. This singular event is the typhoon Vamei which formed over the equatorial South China Sea (around $1.5^{\circ} \mathrm{N}$ ) on 26 December 2001 (e.g. Chang et al., 2003; Chambers and Li, 2007). Chang et al. (2003) indicated that the persistence of the cold surge over the South China Sea and the quasi-stationary location of the Borneo vortex over the sea for more than 1 week were the necessary pre-conditions for this exceptional case of tropical cyclogenesis. Chambers and Li (2007) ran a model simulation and diagnosed that rapid development in the potential vorticity is responsible for the typhoon generation.

While tropical cyclogenesis rarely occurs over the equatorial South China Sea, the formation of heavily precipitating meso- $\beta$ convective systems in the presence of Borneo vortices is a common occurrence and brings heavy rainfall to the surrounding coastal regions during the boreal winter monsoon. There is room for more research to understand the formation and the organization of these smaller but more frequent systems. While Chen et al. (2012) showed that the interannual variation in rainfall in the region is related to the synoptic-scale cyclonic disturbances over and around the South China Sea, the mechanisms through which mesoscale convective systems can develop within the disturbances have not been clarified. Given that there are few diagnostic or dynamical analyses on this topic, we shall explore the mechanism behind the development of the Borneo vortex over the equatorial South China Sea and the associated generation and organization of deep cumulus convection.

In this paper, we examine the physical and the dynamical connections among different spatial scales: the synoptic scale for the monsoon cold surge, the meso- $\alpha$ scale for the Borneo vortex and the meso- $\beta$ scale for cumulus convection. In the first part of the paper, we elucidate through use of reanalysis data and satellite observations, the difference in the synoptic-scale anomalies during cold surge events and reveal the dynamical relation between the cold surge, the Borneo vortex and mesoscale convective systems. This gives us an idea on how the cold surge creates a favourable synopticscale condition both dynamically and thermodynamically for 
the generation of the Borneo vortex heralding cumulus convection and heavy rainfall in the Maritime continent.

The second part of this paper involves a numerical experiment using a non-hydrostatic model in order to examine how deep cumulus convection can be formed in the presence of a Borneo vortex during a cold surge event, based on the favourable conditions for Borneo vortex formation inferred from the results of the first part. Such mesoscale details cannot be captured by the low-resolution of data sets available in this region. Because the Borneo vortex is forced by the cold surge mechanically (which is unlike a typical tropical cyclone or typhoon), we analyse the vorticity tendency budget to investigate the mechanism of growth and maintenance of the Borneo vortex. In addition, our analysis of the divergence tendency budget gives further understanding of the mechanism, because divergence and vorticity tendencies describe together the dynamical evolution of a fluid. Because the Borneo vortex is essentially a result of the dynamical forcing by the cold surge, the divergence tendency budget analysis is able to show some new aspects of the generation and organization of cumulus convection associated with the Borneo vortex at the meso- $\alpha$ scale without detracting from the importance of latent heat release in providing energy, and in maintaining the low-level convergence in the convective cells at the meso- $\beta$ scale.

The remainder of the paper is organised as follows: in Sect. 2, we describe the details of the data sets and model used in this study. We present the results of the data analysis for cold surges and the associated Borneo vortices in Sects. 3 and 4 . The results of the numerical experiment are presented in Sect. 5. In Sect. 6, we synthesize and discuss the results of Sects. 3, 4 and 5. Finally, concluding remarks are made in Sect. 7.

\section{Data and numerical model}

To elucidate the synoptic-scale atmospheric features associated with cold surges, we use the daily Japanese 25 -year Reanalysis (JRA25, Onogi et al., 2007) and the Japanese Meteorological Agency (JMA) Climate Data Assimilation System (JCDAS) data set at $1.25^{\circ} \times 1.25^{\circ}$ horizontal resolution with 23 vertical (pressure) levels in December from 1981 to 2008 (the JRA25 data set is used from 1981 to 2004 while its successor, the JCDAS data set is used from 2005 to 2008). In addition, we analyse the 3-hourly rainfall data for the month of December from 1998 to 2008 obtained from the Tropical Rainfall Measurement Mission (TRMM) version 3B42 data set at horizontal resolution of $0.25^{\circ} \times 0.25^{\circ}$ (Huffman et al., 2007).

The Non-Hydrostatic Model version.2010-May-10 (NHM, Saito et al., 2006, 2007), an operational weather prediction model capable of resolving mesoscale dynamics, developed by the JMA is used to conduct the numerical experiment in this study. Hayashi et al. (2008) evaluated the
NHM simulations of rainfall in the Maritime continent on weather timescales and showed the consistency of the model with observations qualitatively.

In this study, the horizontal and vertical resolutions of NHM are set to be $10 \mathrm{~km}$ and 40 vertical layers (the model top is at $22055 \mathrm{~m}$ using a terrain-following coordinate with 34 levels in the troposphere including levels in the lowest first kilometre). We select the Kain-Fritsch cumulus scheme (Kain, 2004), the six-class cloud microphysics including water vapour, cloud water, cloud ice, rain, snow and graupel (Ikawa and Saito, 1991), the improved Mellor-Yamada level-3 turbulent closure scheme (Nakanishi, 2001; Nakanishi and Niino, 2004, 2006), and the four-layer land surface scheme (Kumagai, 2004). The topography and land use data are obtained from the Global 30 arc second Elevation Data Set (GTOPO30) and the Global Land Cover Characterization (GLCC) of the United States Geological Survey (USGS). Further details of the model configuration such as the boundary and initial conditions of numerical model are given in Sect. 5 .

\section{Composite analysis of cold surge events}

In this section, we examine the observed atmospheric fields when strong cold surges are present over the South China Sea by comparing with the cases when no cold surge events are present using the JRA25/JCDAS reanalyses and TRMM rainfall data.

\subsection{Synoptic-scale atmospheric circulation}

To classify the strong and no cold surge cases, we first compute the Cold Surge (CS) Index (Chang et al., 2005) defined as the daily area-averaged wind speed at $850 \mathrm{hPa}$ in the rectangular domain bounded within 7.5 to $12.5^{\circ} \mathrm{N}$ and 110 to $115^{\circ} \mathrm{E}$. Figure $1 \mathrm{~b}$ shows the daily December CS Index from 1981 to 2008 obtained from the JRA25 and JCDAS reanalyses. We define a CS Index larger (smaller) than the climatology plus (minus) one standard deviation of the CS Index as a strong (no) surge case abbreviated henceforth by SS (NS). SS are present almost every year. They occasionally persist for 1 week or longer, as e.g. in 1984, 1990, 1993, 1998, 1999, 2001, 2005, and 2006. It has been suggested that the strong background monsoon wind played an important role in the formation of tropical typhoon Vamei (Chang et al., 2003) at the record-low latitude of $1.5^{\circ} \mathrm{N}$ in 2001. In addition, the tropical storm Gil (http://www. weather.gov.hk/publica/tc/tc1998.pdf) occurred after a SS over the South China Sea between 9 and 12 December 1998 estimated from the Regional Specialized Meteorological Centre (RSMC) Tokyo Best Track (http:www/jma.go.jp/jma/ jma-eng/jma-center/rsmc-hp-pub-eg/RSMC_HP.htm) of the JMA. The CS Index for January has been examined from 1981 to 2008 as well (not shown) with similar occurrences 

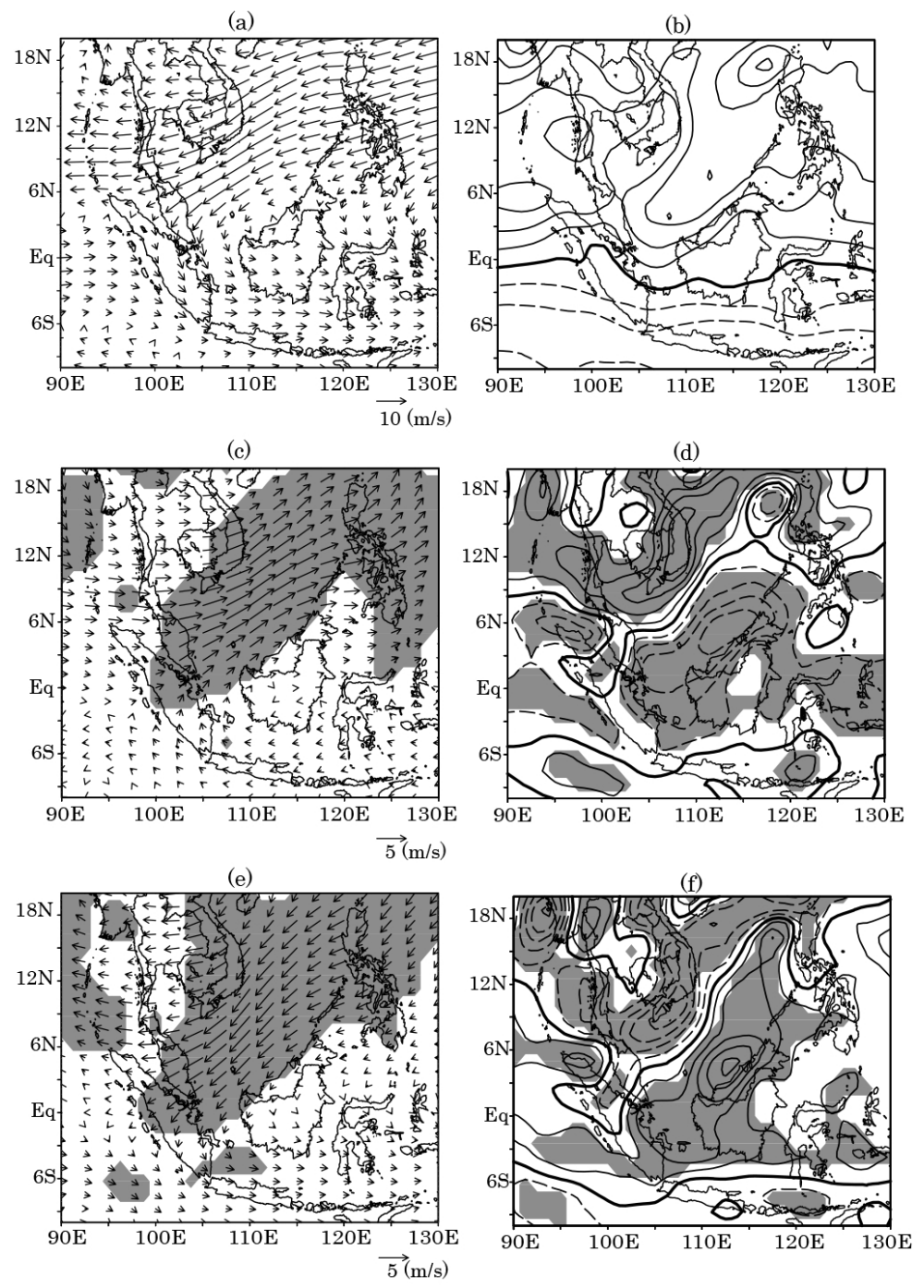

Fig. 2. The climatology (a, b) and composite anomalies during NS (c, d) and SS (e, f) of horizontal wind (a, c, e) and absolute vorticity (b, d, f) at $850 \mathrm{hPa}$ in December obtained from JRA25/JCDAS. The thick black contour denotes zero value. Positive (negative) values are denoted by solid (dashed) lines in (b), (d) and (f). The grey shading denotes statistical significance at $95 \%$ confidence level. Contour interval is $1.0 \times 10^{-4} \mathrm{~s}^{-1}$ for (b) and $0.2 \times 10^{-4} \mathrm{~s}^{-1}$ for (d) and (f).

of SS and NS albeit under different climatological wind conditions.

We exclude those days of SS associated with the two extreme cases of Vamei (20-24 December 2001) and Gil (58 December 1998) from our analysis so as to focus on the typical cases of mesoscale circulation and convection associated with strong cold surges without being biased by the rare extreme events which may involve atypical tropical cyclogenetic dynamics. Thus, the number of SS and NS available for our composite study is 133 and 156 days respectively for the month of December from 1981 to 2008. This translates to 15 and $18 \%$ in terms of frequency of occurrences of SS and NS events respectively.

In the climatology shown in Fig. 2a, the northeasterly winter monsoon winds prevailing over the South China Sea turn northwesterly when they extend into the Java Sea due to the change in the sign of Coriolis parameter across the Equator. During SS (NS), Fig. 2e (Fig. 2c) shows how the winter monsoon is reinforced (weakened) over the South China Sea and to a lesser extent over the Java Sea. The climatology in Fig. 2b shows an enhanced positive absolute vorticity extending from the west of Luzon Island of the Philippines over the South China Sea towards the Equator. During SS (NS), Fig. 2f (Fig. 2d) shows positive (negative) difference in absolute vorticity over the South China Sea off the northwestern coast of Borneo and between Sumatra and Borneo, while negative (positive) difference is found around Indochina. The distribution of the absolute vorticity difference is approximately opposite during NS and SS. The ratio of the difference in absolute vorticity to climatology of absolute vorticity 
is about $30 \%$ in both the SS and the NS off the northwestern coast of Borneo.

\subsection{Synoptic-scale atmospheric transport}

We diagnose from the reanalyses the isobaric divergence of absolute vorticity flux defined as $\nabla_{\mathrm{p}} \cdot\left(\boldsymbol{V} \zeta_{\mathrm{a}}\right)$, where $\boldsymbol{V}$ is the horizontal wind vector $(u, v), \zeta_{\mathrm{a}}$ is the cross-isobaric component of the absolute vorticity, and $\nabla_{\mathrm{p}}$ is the isobaric gradient operator. The isobaric framework is adopted here because the solenoid term in the vorticity equation when expressed in height coordinate is absent in the pressure coordinate form of the equation. This allows us to simplify the vorticity budget analysis in Sect. 5. We describe the difference between SS/NS composite and climatology in this section.

Strong convergence of absolute vorticity flux is located over the South China Sea east of Indochina and the Malay Peninsula during SS while strong divergence of similar magnitude is found further north in the west of Luzon Island (Fig. 3a). This indicates that as the winter monsoon blows from northeast to southwest (Fig. 2a and c), high absolute vorticity is transported southwestward from the northern tropical latitudes toward the Equator. In particular, the anomalous isobaric convergence of absolute vorticity flux in the equatorial South China Sea between the Malay Peninsula and Borneo ( 0 to $5^{\circ} \mathrm{N}$ and 100 to $105^{\circ} \mathrm{E}$ ) extends to the northwestern coast of Borneo due to the enhanced vorticity transport. At lower levels such as $925 \mathrm{hPa}$, this patch of anomalous flux convergence further extends northeastward along the Borneo coast to around $115^{\circ} \mathrm{E}, 6^{\circ} \mathrm{N}$. Averaged between 0 and $4^{\circ} \mathrm{N}$, the anomalous flux convergence is largest in the lower troposphere ( $\sim 700 \mathrm{hPa}$ or larger) over the equatorial South China Sea between 100 and $110^{\circ} \mathrm{E}$ during SS (Fig. 3c), increasing the ambient absolute vorticity.

Next, we examine the moist static energy, $E_{\mathrm{m}}=g Z+$ $c_{\mathrm{p}} T+L q$ (g: gravitational acceleration, $Z$ : geopotential height, $c_{\mathrm{p}}$ : specific heat at constant pressure, $T$ : temperature, $L$ : latent heat of condensation, $q$ : specific humidity). This quantity serves as an indicator for potential activity of moist cumulus convection and associated rainfall in the Borneo vortices. The isobaric divergence of moist static energy flux anomalies at $1000 \mathrm{hPa}$ during SS, defined as $\nabla_{\mathrm{p}} \cdot\left(\boldsymbol{V} E_{\mathrm{m}}^{\prime}\right)$ (where the prime denotes deviation from the climatological value), has a similar pattern to that of absolute vorticity flux anomalies (Fig. 3a and b): the moist static energy transported equatorward by the northeast monsoon converges over the equatorial South China Sea during SS. Note that the anomalous flux convergence is most significant below $800 \mathrm{hPa}$ (Fig. 3d). Thus, moist static energy is anomalously transported to the equatorial South China Sea by strong cold surges from the evaporative sources in northern South China Sea. This supply of moist static energy maintains moist convection in the equatorial South China Sea where vertical mixing by convective updrafts and downdrafts as well as net vertical transport to the upper troposphere removes moist static
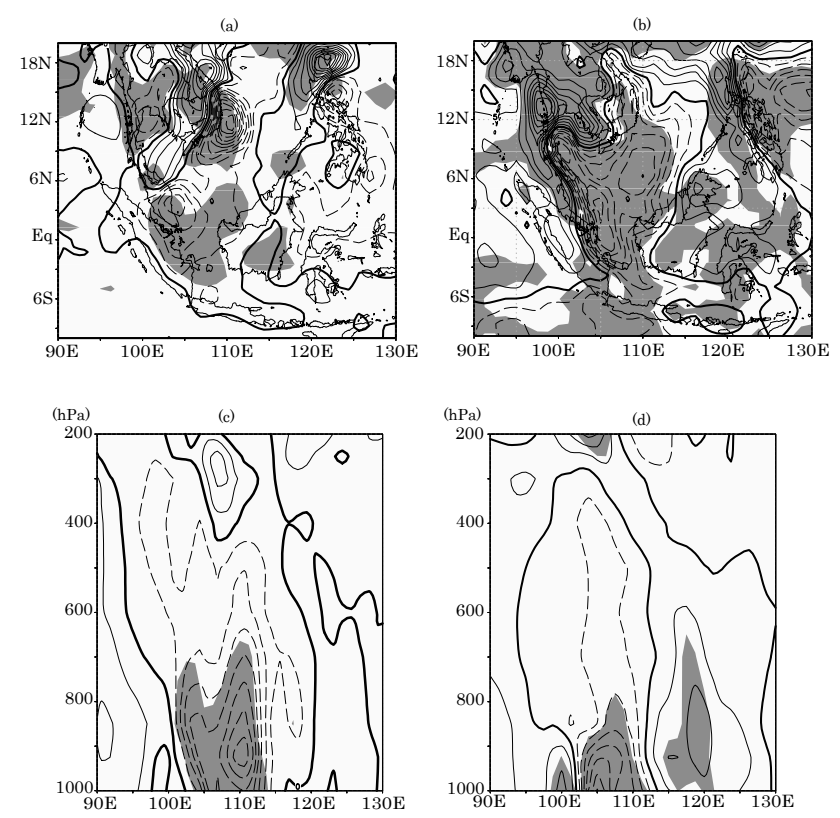

Fig. 3. (a)-(b) Divergence of absolute vorticity and moist static energy flux anomalies (SS composite minus climatology) obtained from JRA25/JCDAS at $850 \mathrm{hPa}$ in December. (c) and (d) Pressurelongitude sections of (a) and (b) respectively averaged between $0^{\circ}$ and $4^{\circ} \mathrm{N}$. Black solid (dashed) line is positive (negative) value. Contour interval is $5 \times 10^{-5} \mathrm{~s}^{-1} \mathrm{day}^{-1}$ for (a), $5 \times 10^{4} \mathrm{~J}_{\text {day }}{ }^{-1}$ for (b), $2 \times 10^{-5} \mathrm{~s}^{-1} \mathrm{day}^{-1}$ for (c), and $5 \times 10^{4} \mathrm{~J} \mathrm{day}^{-1}$ for (d). Thick black contour denotes the value of zero. The grey shading is statistical significance at $95 \%$ confidence level for the difference from the climatology.

energy in the lower troposphere and hence stabilizes the atmospheric column.

Both the convergence of absolute vorticity and moist static energy fluxes over the equatorial South China Sea under such SS conditions may be favourable for spinning up the Borneo vortex and sustaining cumulus convection: the tendency to increase ambient absolute vorticity encourages stronger vorticity generation by vortex stretching, while there is ample moist static energy supply to sustain convection and latent heat release, which underlies the buoyancy of air parcels causing vertical motion and vortex stretching. To test whether the SS conditions favour the formation of the Borneo vortex, we conducted the semi-idealized experiment described in Sect. 5.

\subsection{Rainfall and its diurnal cycle}

Intense rainfall over the western Maritime Continent in December is prominent over the central South China Sea, the eastern Malay Peninsula, northwestern coastal sea of Borneo and the Java Sea (Fig. 4a). The rainfall over these regions shows considerable variability with the cold surge activity (Fig. $4 \mathrm{~b}$ and c). 

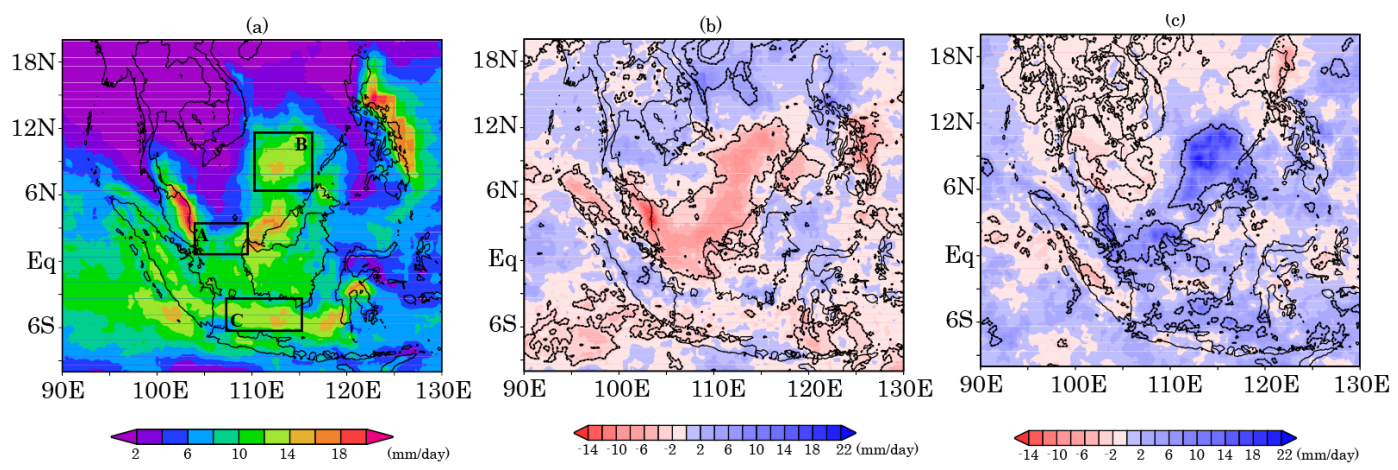

Fig. 4. (a) The climatology of daily accumulated rainfall obtained from TRMM 3B42 and anomalies during NS and SS from the climatology in (b) and (c), respectively. The black dotted lines denote statistical significance at $90 \%$ confidence level. The boxes A-C in (a) are for the area averages in Fig. 5.
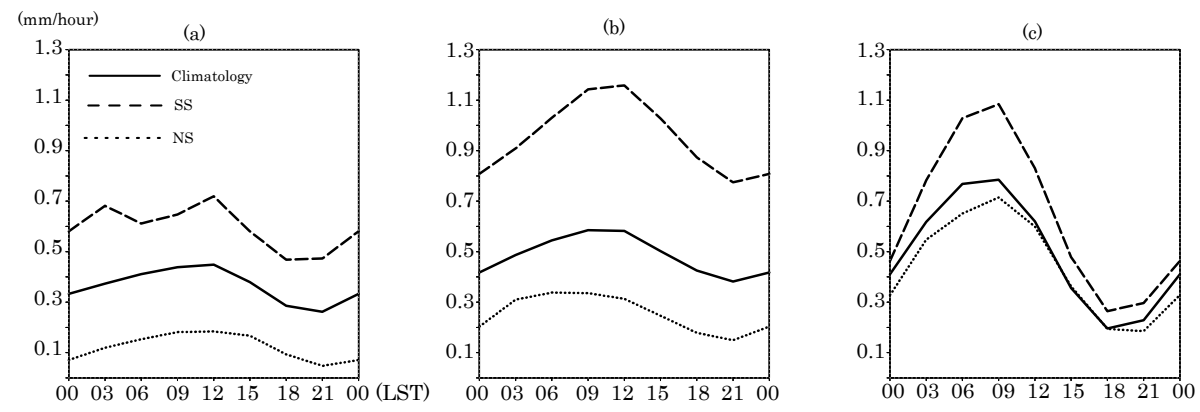

Fig. 5. Three-hourly rainfall averaged over (a) the equatorial South China Sea (box A), (b) the South China Sea north of Borneo (box B), and (c) the Java Sea (box C) during NS (long-short dashed line), climatology (solid line), and SS (dashed line).

Over the land and coastal seas, the rainfall has a strong diurnal cycle brought about by sea/land breeze circulation (e.g. Mak and Walsh, 1976; Hadi et al., 2002; Joseph et al., 2008; Teo et al., 2011). In contrast, the diurnal cycle of the rainfall over the South China Sea has smaller amplitude especially near the Equator (see the boxes in Fig. 4a and the solid lines in Fig. 5). This may be because the local SST diurnal fluctuation is small over the open sea and the influence of the landmass in the form of land breeze is either weak or absent. During SS (NS) the rainfall over the equatorial South China Sea is almost uniformly enhanced (reduced) throughout the day (Fig. 5a). In contrast, the climatological rainfall over the Java Sea has a large diurnal cycle and during SS (NS) the rainfall is enhanced (reduced) the most in the morning around 03:00-12:00 LST (06:00-09:00 LST), when the rainfall is maximal (Fig. 5c).

Changes in the diurnal cycle under changing ambient wind have been reported in Qian et al. (2010) and Koseki et al. (2013) over the Java Sea. The essential mechanism for intense rainfall over the Java Sea during the boreal winter monsoon demonstrated in Koseki et al. (2013) is that the seaward land breeze collides with the ambient wind which has a northerly component leading to the peak rainfall occurring in the morning. During strong cold surges, unlike

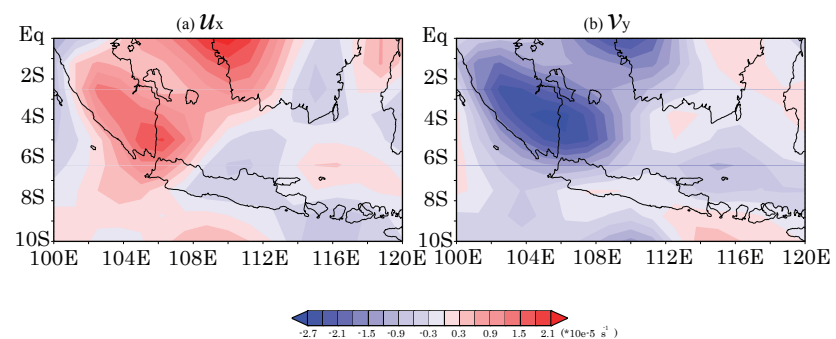

Fig. 6. The difference in horizontal convergence at $850 \mathrm{hPa}$ (shading) between SS and climatology for (a) zonal component and (b) meridional component obtained from JRA25/JCDAS data.

the westerly wind component, the northerly wind component is clearly enhanced in the Java Sea (Fig. 6). Thus, it is dynamically consistent that we see enhanced rainfall in the morning but not so much in the afternoon over the Java Sea (Fig. 5c). We surmise that during SS, the rainfall change over the Java Sea is the result of the interaction of the synopticscale circulation with the local-scale circulation and is unlikely to be directly linked with the mechanisms underlying the rainfall change over the South China Sea. In the same vein of thought, we shall not further investigate the changes in the rainfall over the eastern Malay Peninsula and near 
northwestern Borneo as the local-scale coastal circulation in these areas are as strong as over the Java Sea.

\section{Borneo vortex in JRA25 and JCDAS data}

Since rainfall is intensified the most over the South China Sea during SS roughly where the absolute vorticity anomaly exceeds $0.4 \times 10^{-4} \mathrm{~s}^{-1}$ over (compare Figs. $2 \mathrm{f}$ and $4 \mathrm{c}$ ), one may suspect that a physical relationship may exist between the absolute vorticity and rainfall activity. In particular, we are interested in those situations when the high absolute vorticity manifests as a strong Borneo vortex.

We define the Marine Borneo Vortex (MBV) Index as the averaged absolute vorticity at $850 \mathrm{hPa}$ averaged over an area bounded by 0 to $4^{\circ} \mathrm{N}$ and 105 to $110^{\circ} \mathrm{E}$ covering the equatorial South China Sea between the Malay Peninsula and Borneo. This is because the absolute vorticity flux convergence is remarkable in this region (as indicated in Fig. 3a) and the cyclonic vortex tends to be induced there. The MBV Index tends to be strong when the CS Index is strong (Fig. 7) and vice versa. The correlation coefficient between CS and $\mathrm{MBV}$ indices is 0.35 in December and 0.49 in January, both of which are statistically significant at the $95 \%$ confidence level. This suggests that a strong cold surge which transports high absolute vorticity from the north tends to spin up a strong Borneo vortex over the equatorial South China Sea. This idea is supported by the dynamical experiments of Lim and Chang (1981).

Next, we define a strong cold surge event and a strong marine Borneo vortex event as a continuous period when the daily mean value of both the CS and MBV indices are larger than one standard deviation from their respective climatological mean. A strong cold surge is said to spin up a strong Borneo vortex in the equatorial South China Sea only if the two events overlap in time and the former starts at the same time or earlier than the latter. With such definitions, we found that 58 out of the 133 days of SS identified previously are related directly to the strengthening of the Borneo vortex in the equatorial South China Sea. For three of these days, the Borneo vortex is located north of $5^{\circ} \mathrm{N}$ and takes on a more elongated shape, which is rather exceptional. Therefore, subsequent composite analyses use only the other 55 days of the diagnosed vorticity and divergence. Only 16 days of the satellite rainfall data are used because of TRMM's shorter temporal coverage.

Figure 8a shows that strong Borneo vortices during SS occur mostly around the west of Borneo near the Equator between $5^{\circ} \mathrm{N}$ and $2^{\circ} \mathrm{S}$ where tropical cyclones do not develop (except for the singular case of the Typhoon Vamei) The technical details of how the location of the vortex centre is obtained are explained in Appendix A. This distribution of vortex centres is similar to that obtained by Chang et al. (2003), although they identified Borneo vortices without regard to the strength of the cold surge. Figure $8 \mathrm{~b}$ shows that
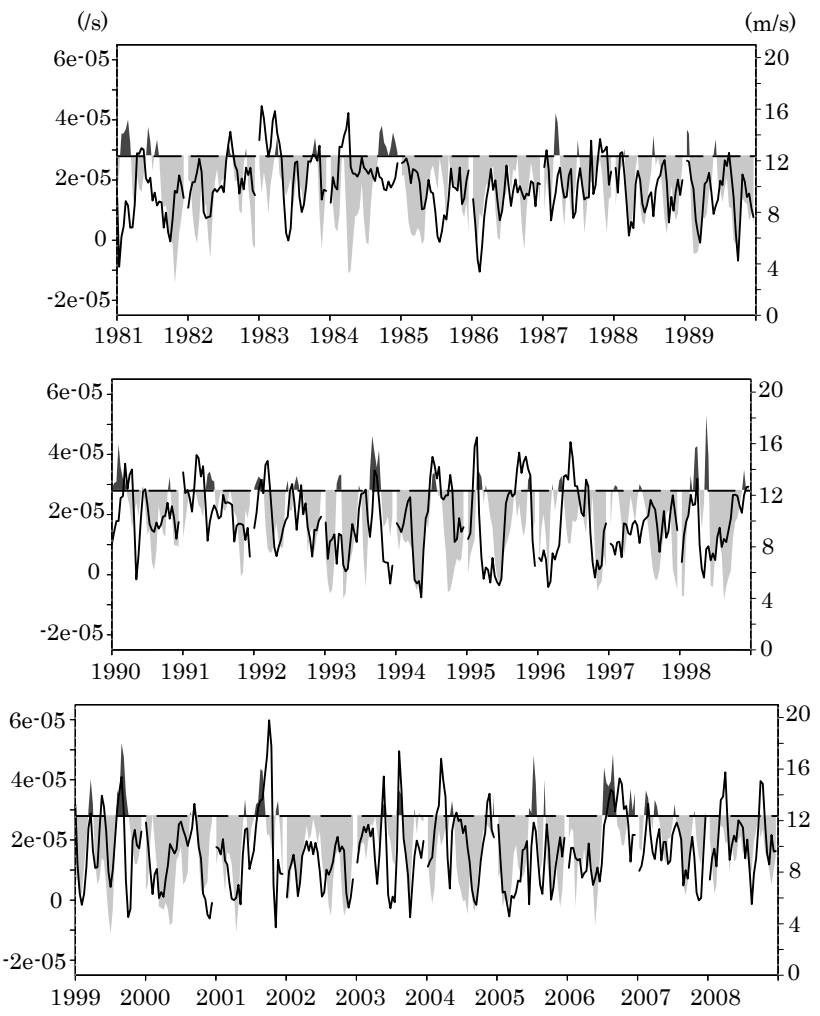

Fig. 7. The temporal sequences of daily CS Index (shade) and the Marine Borneo Vortex (MBV) Index (line) in December obtained from JRA25/JCDAS. Dark (light) shade is CS Index larger (smaller) than climatology plus one standard deviation of CS Index. The dashed lines denote the climatology plus one standard deviation of MBV Index. The lines are disjoint between years.

the wind field is not axisymmetric in the composited Borneo vortex, with strong northeasterlies in the northeast sector, which is attributed to the strong cold surge. The maximum of the absolute vorticity is located slightly northwest from the vortex centre and the ridge of high absolute vorticity extends northeastward and, to a much lesser extent, westward and southeastward. The strongest convergence is at the north of the centre but the convergence is also relatively strong in the southern, western and northeastern sectors (Fig. 8c) where strong wind prevails (Fig. 8b). On the other hand, weak divergence is located southeast of the composited vortex overlapping with a patch of weakly negative absolute vorticity. The pattern of intense rainfall is approximately consistent with the pattern of strong convergence with a slight northeastward displacement of the former from the latter.

As the resolution of the JRA/JCDAS is low and vortices of different sizes and shapes are composited in Fig. 8b and c, it is hard to discern any clear relation between absolute vorticity, wind convergence and rainfall in a Borneo vortex from the above results. 

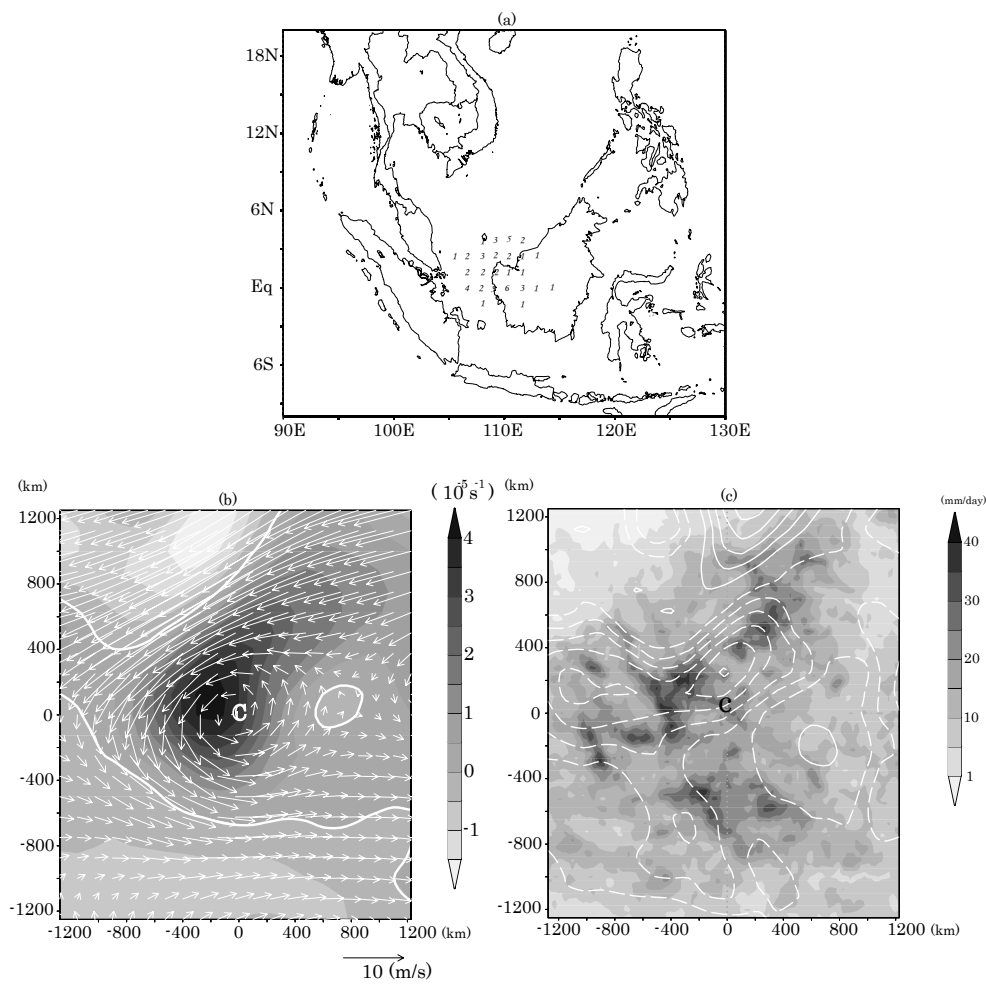

Fig. 8. (a) The location of Borneo vortex centre obtained from JRA25/JCDAS. The grid numbers give the number of days that the centre is located at each grid. (b) The composite of absolute vorticity (shaded) and horizontal wind (vector) at $850 \mathrm{hPa}$ from JRA25/JCDAS around the centre of Borneo vortex. The white thick contour denotes the value of zero of absolute vorticity. (c) The composite of horizontal divergence (contour interval is $10^{-6} \mathrm{~s}^{-1}$ ) at $850 \mathrm{hPa}$ from JRA25/JCDAS and hourly rainfall (shaded) from TRMM around the centre of the Borneo vortex. Solid (dashed) line means positive (negative) value. $\mathrm{C}$ denotes the centre of the composite Borneo vortex.

\section{Semi-idealized experiment for the Borneo vortex}

Based on the CS and MBV indices obtained in the preceding section, Borneo vortices occur with a probability of $44 \%$ (=58 days out of 133 days) during strong cold surges. The presence of Borneo vortices may be a result of the enhanced vorticity flux convergence in the lower troposphere discussed in Sect. 3.2. In this section, we present the results of a numerical experiment using NHM (see Sect. 2) designed to investigate into this possibility as well as how rainfall is organized by the strong cold surge and the Borneo vortex.

\subsection{Experimental design}

We use the composite reanalysis fields for all 133 days of SS as the model's initial and (constant) boundary conditions to represent the synoptic conditions under which a Borneo vortex forms over the equatorial South China Sea. Although one may use the composited fields from the 55 or 58 days where Borneo vortices are actually present (see Sect. 4), we opt for the earlier set of initial and boundary conditions since a Borneo vortex is spun up in our model using them. Furthermore, this set of initial and boundary conditions better represents the conditions during SS. The reason as to why the model is able to generate a vortex, despite using initial and boundary conditions obtained from a set of SS events that includes days where no Borneo vortex forms is due to the anomalous convergence of the absolute vorticity flux over the equatorial South China Sea (Fig. 3a); by holding such lateral boundary conditions constant during the model simulation, we maintain a strong cold surge in the model that keeps supplying absolute vorticity and moist static energy over the equatorial South China Sea. Those 75 days where no Borneo vortices were generated in the real atmosphere are due to the lack of such persistent "lateral boundary forcings".

The integration period is 11 days and we set an expediential initialization date-time of 15 December, 00:00 UTC for the model's diurnally and seasonally dependent radiation scheme. The model spins up effectively within the first day of integration. Horizontal and vertical resolutions are $10 \mathrm{~km} \times 10 \mathrm{~km}$ at the Equator using Mercator projection and 40 layers in terrain-following coordinate. The centre of domain is at $\left(110^{\circ} \mathrm{E}, 2.5^{\circ} \mathrm{N}\right)$ and with $300 \times 300$ grid points (Fig. 9a). Realistic land-sea mask and terrain height are used. Henceforth, we call this experiment the semi-idealized experiment. We checked that there was no systematic trend in total mass within the domain despite the prescription of boundary winds. 

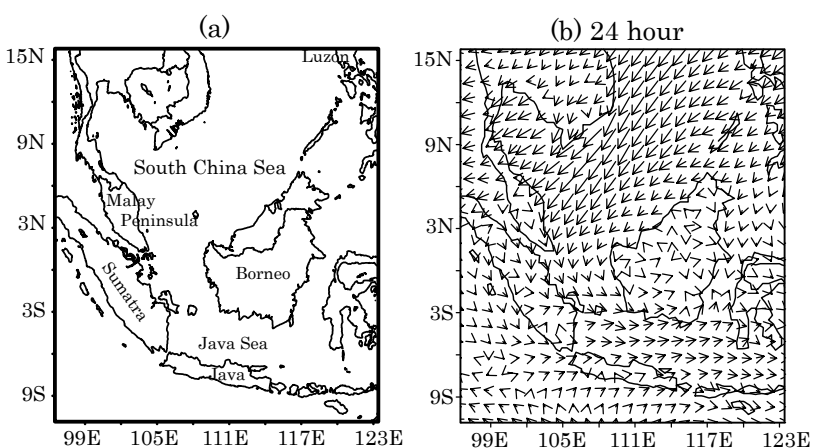

(e) 96 hour

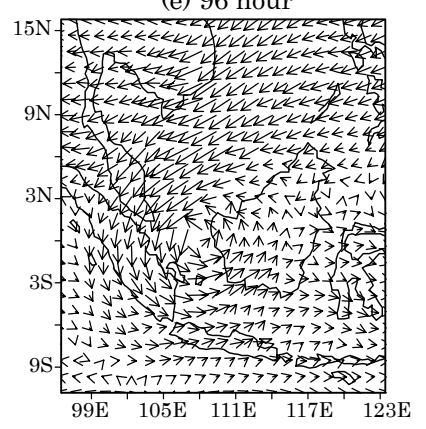

(f) 120 hour

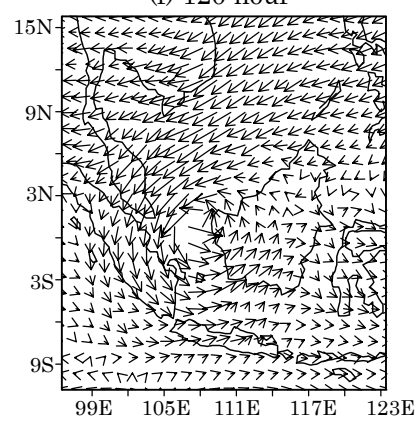

(c) 48 hour

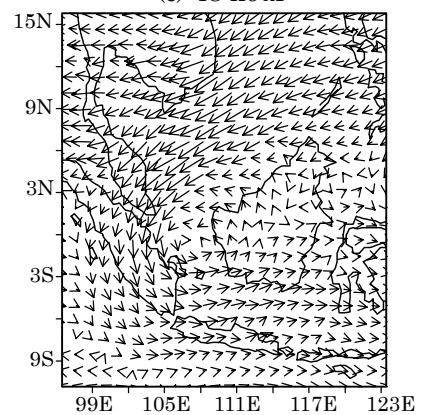

(g) 144 hour

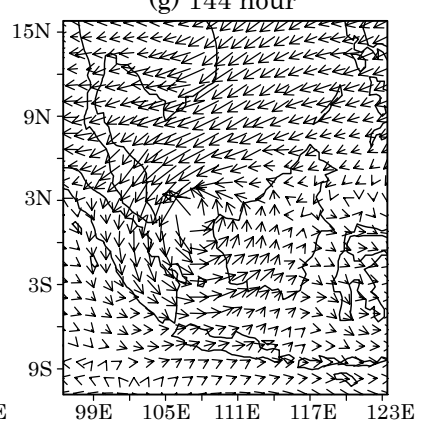

(d) 72 hour

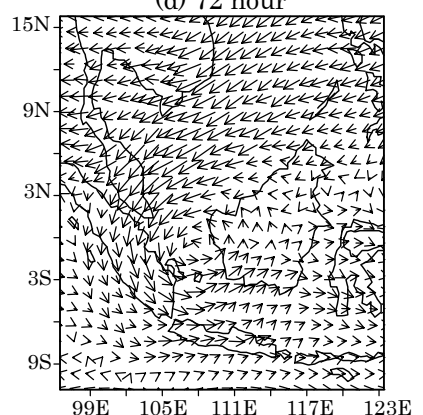

(h) 168 hour

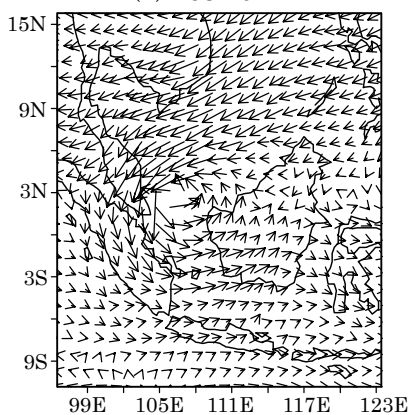

(i) 192 hour

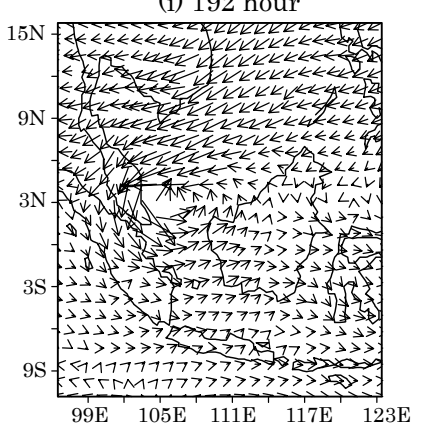

(j) 216 hour

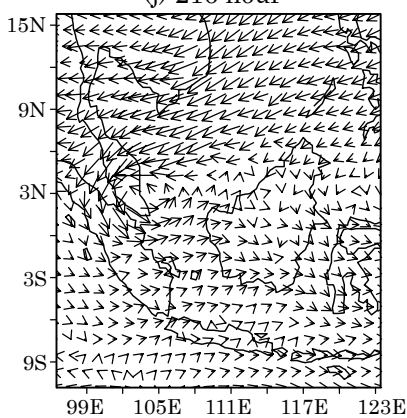

(k) 240 hour

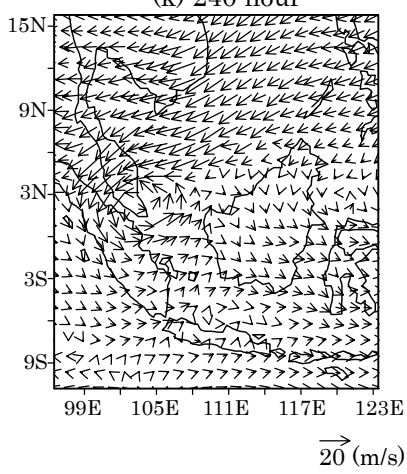

(1)

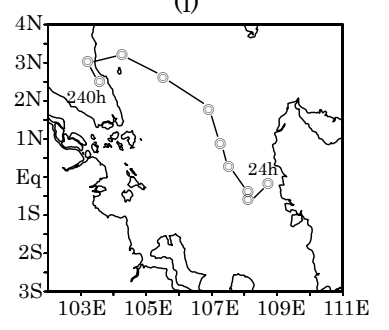

Fig. 9. (a) The domain of the semi-idealized experiment. (b)-(k) 24-hourly temporal evolution in the simulated Borneo vortex shown by horizontal wind at $850 \mathrm{hPa}$ from 24 to $240 \mathrm{~h}$ after initialization. (l) shows the 24-hourly cyclone track.

\subsection{Simulated Borneo vortex}

Figure $9 \mathrm{~b}-\mathrm{k}$ show the formation and westward movement of the vortex over the equatorial South China Sea in the semiidealized experiment. At $24 \mathrm{~h}$, meridional wind at $850 \mathrm{hPa}$ is almost southward over the equatorial South China Sea and the Borneo vortex has barely formed yet. Between 48 and $72 \mathrm{~h}$, weak southerly is detected around 108 to $109^{\circ} \mathrm{E}$ and $1.5^{\circ} \mathrm{S}$ to $0^{\circ} \mathrm{N}$ and cyclonic circulation is generated around the Equator over the sea. This cyclonic circulation is intensified by $96 \mathrm{~h}$. At this stage, the cyclonic circulation resembles the typical Borneo vortex and the vortex is quasi-stationary.
At $120 \mathrm{~h}$, the vortex strength is enhanced more significantly. From 144 to $192 \mathrm{~h}$, the Borneo vortex moves slowly northwestward. This well-developed vortex has a spatial scale between a few hundred to a thousand kilometres, i.e. at the meso- $\alpha$ scale. This meso- $\alpha$ cyclone is unlike a tropical cyclone which is more intense and has distinct dynamics. Between 216 and $240 \mathrm{~h}$, the cyclone reaches over the Malay Peninsula and weakens. Figure 91 illustrates the 24 hourly track of the cyclone centre (defined in Appendix A) from 24 to $240 \mathrm{~h}$.

Figure 10a and $\mathrm{b}$ illustrate time sequences of areaaveraged absolute vorticity at $850 \mathrm{hPa}$ and hourly rainfall 
within $100 \mathrm{~km}$ of the cyclone centre. The absolute vorticity is less than $10^{-4} \mathrm{~s}^{-1}$ until $50 \mathrm{~h}$ and becomes gradually intensified until around $140 \mathrm{~h}$. After that, the cyclone is more or less mature. From $190 \mathrm{~h}$, it weakens rapidly and remains as a weak vortex after $223 \mathrm{~h}$. Rainfall shows a clear diurnal cycle (roughly consistent with the diurnal cycle in Fig. 4a) and the diurnal peak rainfall intensity appears to follow the trend of the absolute vorticity of the meso- $\alpha$ cyclone. Based on these temporal sequences of the cyclone, we can divide the life cycle of the cyclone into three stages: a developing stage (50 to $140 \mathrm{~h}$ ), a mature stage (141 to $190 \mathrm{~h}$ ), and a decaying stage (191 to $223 \mathrm{~h}$ ).

Figure 11 shows the horizontal distribution of temporal mean of hourly accumulated rainfall around the cyclone centre at each stage. In the developing stage (Fig. 11a), rainfall is intense just west of the cyclone centre and extends northward $\sim 150 \mathrm{~km}$. In the mature stage (Fig. 11b), the rainfall adjacent to the cyclone centre becomes more intense and a welldeveloped comma-shaped rainband extends from the centre northward, northeastward and then eastward to reach a distance of $250 \mathrm{~km}$ from the centre. This comma-shaped rainband is located only in the northern part of the cyclone and its localization is discussed in Sect. 6. In the decaying stage (Fig. 11c), the rainfall around the centre is reduced significantly and the distribution is relatively widespread but still mostly in the northern part of the cyclone. Throughout the three stages of the simulation, no "eye" formation occurs, unlike in typhoons which form in higher tropical latitudes and in the Typhoon Vamei which formed in this region.

Compared with the composite of the Borneo vortex in the TRMM data set (Fig. 8c), the rainfall is much more localized in the northern and northeastern sector, and is one order of magnitude more intense in our semi-idealized experiment. This is expected from the higher resolution of the model which is able to capture the meso- $\beta$-scale dynamics. On the other hand, TRMM rainfall estimates could be too low due to interfering thick and widespread clouds in the Borneo vortex during data retrieval. Moreover, no two actual Borneo vortices have exactly matching intense rainfall regions and so a composite always reflects lower rainfall magnitudes than single vortices.

The southern patch of relatively intense rain in the TRMM composite (Fig. 8c) is not seen in the model simulation (Fig. 11b). This may be because the centres of actual Borneo vortices are distributed rather widely around the Equator in Fig. $8 \mathrm{c}$ and so the southern part of some vortices (i.e. 400 $800 \mathrm{~km}$ south of the centre) spans the Java Sea where rainfall arises mainly due to local land breeze circulation (see Sect. 3.3) and is captured in the composite. But in the model, the vortex centre lies between 2 and $3^{\circ} \mathrm{N}$ in the mature stage (from 144 to $192 \mathrm{~h}$ in Fig. 91) and the simulated vortex is about 2-3 times smaller. So the southern part of the simulated vortex (i.e. $200-300 \mathrm{~km}$ south of the centre) does not reach the Java Sea and therefore there is no southern intense rain patch.
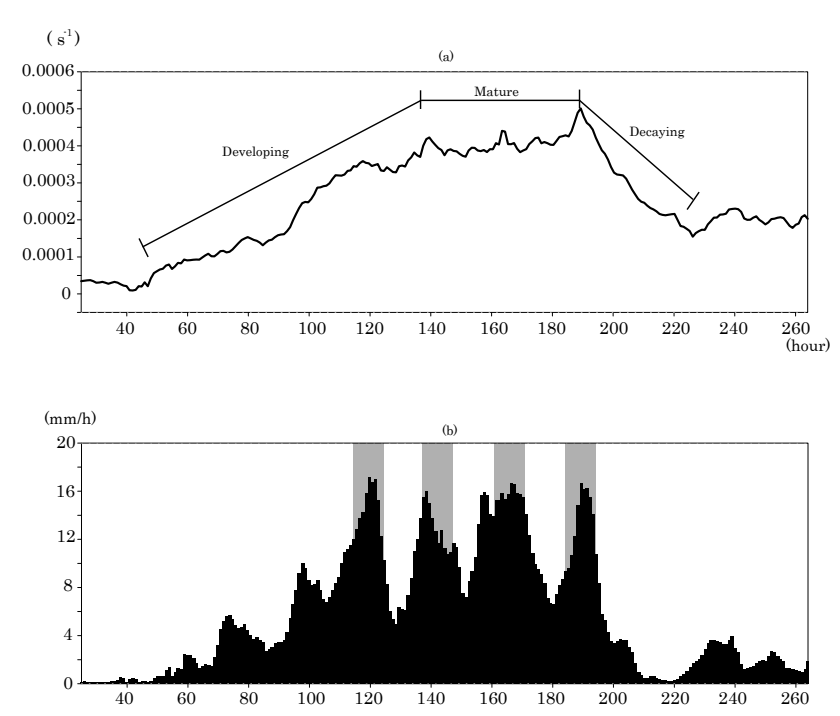

Fig. 10. The time sequences of (a) absolute vorticity at $850 \mathrm{hPa}$ and (b) hourly rainfall averaged within a radius of $200 \mathrm{~km}$ of the centre of simulated meso- $\alpha$ cyclone. The grey bars denote the time from 00:00 to 12:00 LST.

The fact is that the Borneo vortices for the 16 days composited in the TRMM data record show different horizontal size, shape and centre locations and the rainfall also has much spatial variance around the vortex centre. Conversely, our simulated vortex is one idealized case and has quite a clear feature of a rainband. Nonetheless, some qualitative features, such as the relatively strong rainfall in the strong convergence zone northeast of the vortex centre, are seen in both our simulation and the observations.

\subsection{Vertical structure of the meso- $\alpha$ cyclone}

We explore the structure of the axisymmetric vertical structure of the meso- $\alpha$ cyclone by averaging the atmospheric variables at equal distances from the cyclonic centre at the mature stage, when the cyclone is most intense. Figures 12a and $\mathrm{b}$ illustrate the axisymmetric tangential and radial winds. Tangential velocities beyond $24 \mathrm{~m} \mathrm{~s}^{-1}$ are seen just within a $50 \mathrm{~km}$ radius, which is comparable to that of a typical typhoon over the tropical Pacific Ocean (Frank, 1977). However, such strong winds are limited to the lower troposphere (below $\sim 750 \mathrm{hPa}$ ) and the tangential wind rapidly weakens in the upper troposphere $\left(<20 \mathrm{~m} \mathrm{~s}^{-1}\right.$ above $\left.\sim 600 \mathrm{hPa}\right)$. Thus, the meso- $\alpha$ cyclone in our experiment is shallower compared to a typical typhoon where winds remain quite strong even in the upper troposphere (Frank, 1977). There is radial inflow mainly below $\sim 900 \mathrm{hPa}$ and radial outflow mainly above radial $\sim 300 \mathrm{hPa}$. The distribution and magnitude of radial wind are similar to those of typical tropical typhoons over the Pacific Ocean (Holland and Merrill, 1984). The wind speeds are much stronger and the spatial scale is much smaller in our simulation than in the composite 

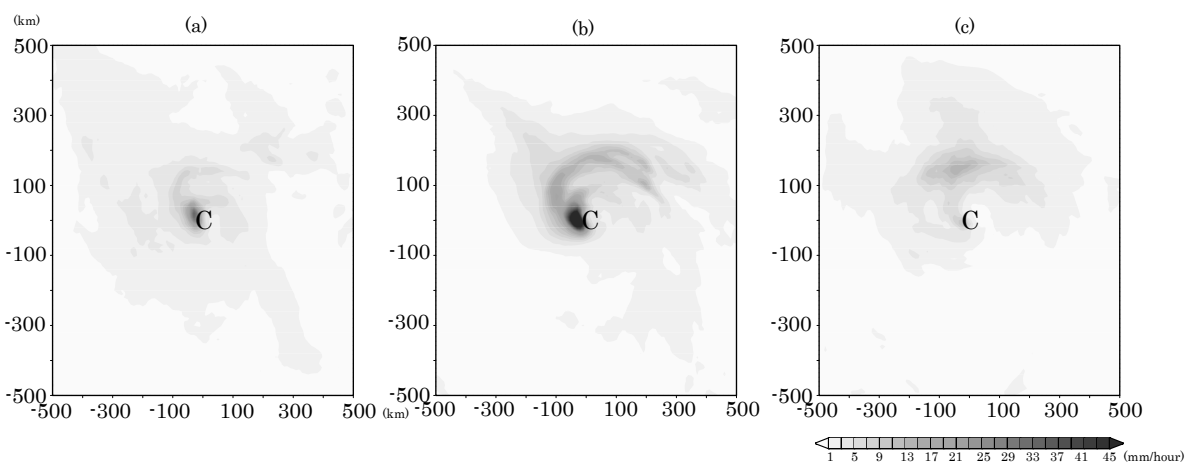

Fig. 11. The temporal mean of hourly rainfall around the centre of simulated meso- $\alpha$ cyclone in the (a) developing stage, (b) mature stage, and (c) decaying stage. $\mathrm{C}$ denotes the centre of composite meso- $\alpha$ cyclone.
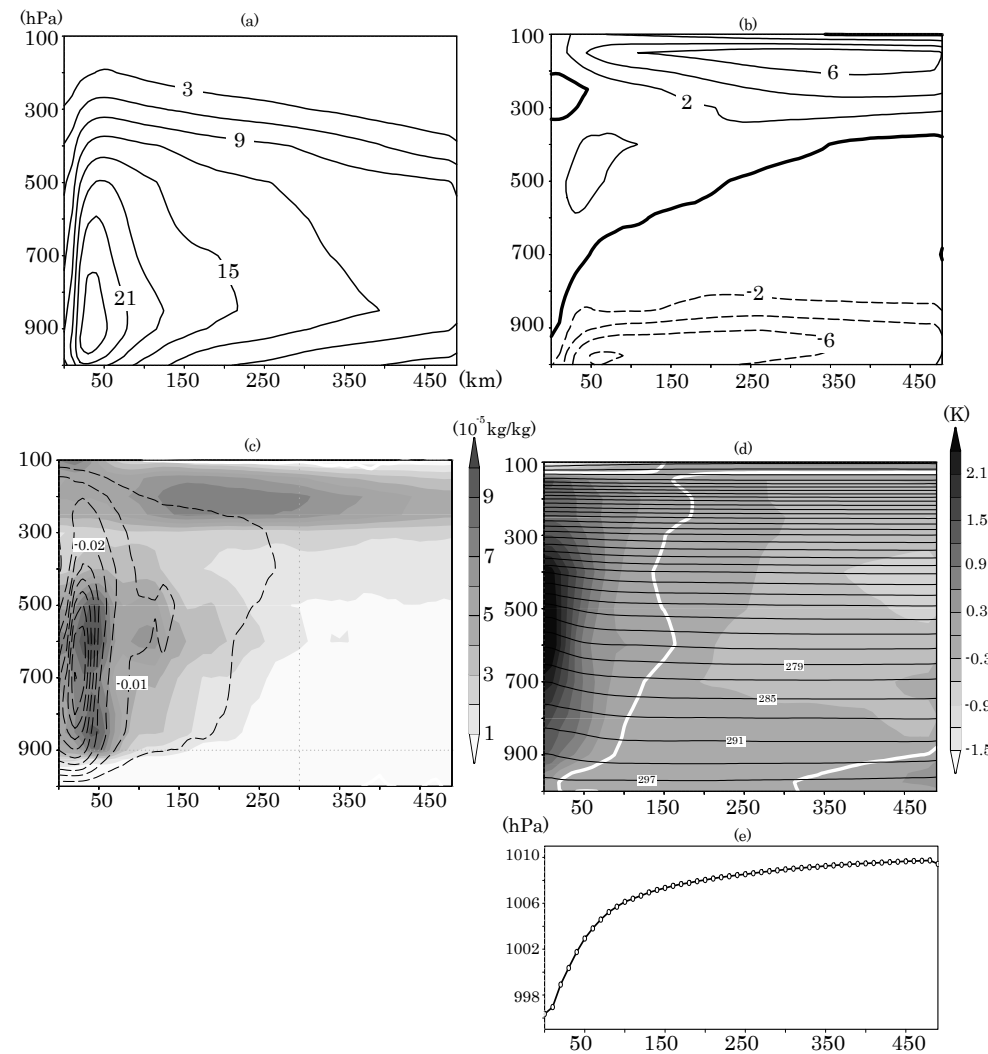

Fig. 12. The pressure and radial sections of axisymmetric components of (a) tangential wind, (b) radial wind, (c) mixing ratio of cloud water (liquid plus ice, shade) and vertical velocity (contour, interval is $0.005 \mathrm{hPah}^{-1}$ ), (d) temperature (contour) and temperature deviation from radial mean (shaded). The white thick contours in (d) are the value of zero of temperature deviation. (e) The axisymmetric component of sea level pressure.

Borneo vortex from the JRA25/JCDAS (not shown), probably because the global model on which the JRA25/JCDAS is based lacks the resolution to support the downscale cascade of kinetic energy in the mesoscale which serves to strengthen and tighten the vortex.

Figure 12c shows the axisymmetric component of mixing ratio of cloud liquid water plus cloud ice (shaded) and vertical velocity (contour) around the cyclone centre in the mature stage. One maximum of cloud water is detected between 900 and $500 \mathrm{hPa}$ around the radius of $50 \mathrm{~km}$. This maximum of cloud water is associated with the deep convection and heavy rainfall adjacent to the cyclone centre (Fig. 11b). Our simulated cyclone does not have a cloud-free region in the centre and the surface pressure depression is not strong, indicating that the structure of our meso- $\alpha$ cyclone (the Borneo vortex) is different from that of typical mature typhoons, 
although the intensity of radial and tangential wind in the lower troposphere is comparable to them (e.g. Frank, 1977; Holland and Merrill, 1984). The location of the maximum of vertical velocity is roughly consistent with that of cloud water, especially after making allowance for possible outward displacement of hydrometeors due to centrifugal forces in the cyclonic circulation. This strong upward motion is consistent with the warm anomaly (Fig. 12d) due to latent heat release which can be attributed to the deep cumulus convection around the vortex centre. While the axisymmetric vertical velocity shows negative values (upward), weak nonaxisymmetric positive vertical velocity (downward) can be detected around the centre as part of the local organization of convective downdrafts (not shown). The other maximum of cloud water (mostly in the ice phase) is seen between 300 and $100 \mathrm{hPa}$ and has a large radial extent from 100 to $350 \mathrm{~km}$. This is because the radial wind at this level is centrifugal and the cloud ice is advected outward. Thus, this upper tropospheric cloud can be categorized as one of the anvils associated with cumulus convection. Moreover, the horizontal distribution of the cloud liquid water and ice is actually asymmetric around the meso- $\alpha$ cyclone (not shown).

Meanwhile, the depression in sea level pressure (SLP) at the cyclone centre corresponds well to the positive temperature anomaly aloft as is expected from hydrostatic balance (Fig. 12e). The mesoscale simulation indicates that the central depression could be as much as $13 \mathrm{hPa}$ lower than the ambient SLP, which is an order of magnitude greater than what is recorded in the JRA25/JCDAS data set at synoptic scale (not shown). This is reasonable because most of the pressure drop occurs within $150 \mathrm{~km}$ from the cyclone centre, which is below the limit of the resolution of the JRA25/JCDAS data set.

\section{Analysis and discussion of the numerical experiment}

\subsection{Growth and maintenance of the meso- $\alpha$ cyclone}

To investigate what mechanism leads to the growth of the meso- $\alpha$-scale cyclone, we examine the absolute vorticity dynamics in this section.

Appendix B shows that in the reference frame co-moving with the cyclone centre, the tendency equation for crossisobaric absolute vorticity $\zeta_{\mathrm{a}}$ is

$$
\frac{\partial \zeta_{\mathrm{a}}}{\partial t}=-\left(\boldsymbol{V}_{\mathrm{H}}-\boldsymbol{V}_{\mathrm{C}}\right) \cdot \nabla_{\mathrm{p}} \zeta_{\mathrm{a}}-\omega \frac{\partial \zeta_{\mathrm{a}}}{\partial p}-\zeta_{\mathrm{a}} D-\left(\frac{\partial \omega}{\partial x} \frac{\partial v}{\partial p}-\frac{\partial \omega}{\partial y} \frac{\partial u}{\partial p}\right),
$$

where $\boldsymbol{V}_{\mathrm{H}}$ and $\nabla_{\mathrm{p}}$ are as defined in Sect. 3.2, $\boldsymbol{V}_{\mathrm{C}} \equiv\left(u_{\mathrm{C}}\right.$, $\left.v_{\mathrm{C}}\right)$ is the cyclone velocity estimated from the cyclone track in Fig. 91, $\omega$ is the vertical velocity in pressure coordinate, and $D$ is the isobaric divergence. The right-hand side of Eq. (1) comprises (from left to right) the following forcing terms: (1) horizontal advection (HADV), (2) vertical advection (VADV), (3) stretching of vertical vortex tubes (STRC), and (4) tilting of horizontal vortex tubes (TILT). The cyclone velocity only affects horizontal advection and hence the time tendency in the co-moving frame.

Figures 13a-e show that HADV and VADV contribute negatively to the cyclone development. On the other hand, the terms of STRC and TILT are positive. In particular, STRC is more dominant and is mainly responsible for spinning up the cyclone. The net forcing shows maximum positive tendency west of the absolute vorticity maximum and the cyclone centre, as horizontal convergence maximizes there leading to strong vertical vortex stretching. As a result, the cyclone migrates westward with time.

While the sign of each term is roughly the same in the mature stage (Fig. 13f-j) as in the developing stage, the magnitude of every term, especially STRC, is much larger. Additionally, a positive tendency is seen in the HADV and VADV denoting that advection is bringing high-vorticity air to the cyclone centre from the northwest and from lower levels where the vorticity generation is stronger. TILT shows a north-south dipole structure resulting from the maximum rising motion located at the centre of the dipole under ambient easterly wind shear. The net positive forcing still lies west of the absolute vorticity maximum and the cyclone centre as that is where vertical vortex stretching is the strongest, but a negative tendency is also found in the southwestern and southern sector of the cyclone due to the tilting effect.

Higher up in the atmosphere $(600 \mathrm{hPa})$ in the mature stage (Fig. 13k-o), HADV, VADV and STRC are largely opposite to those at $850 \mathrm{hPa}$ : absolute vorticity is advected upward and westward from the lower levels while horizontal divergence is destroying the vorticity. TILT still has a dipole structure, but in the east-west rather than north-south direction. The net forcing is still positive west of the vorticity maximum and the cyclone centre mainly due to vertical advection from the lower levels. At even higher levels ( $\sim 250 \mathrm{hPa}$, not shown), while the tendency of each forcing term is similar to those at $600 \mathrm{hPa}$, the net forcing is only weakly positive.

In summary, vortex stretching mainly occurs at low levels and the ambient cross-isobaric absolute vorticity is rapidly intensified and advected to the mid-troposphere where it is destroyed by isobaric divergence. This is the primary reason for the spin-up and sustenance of a meso- $\alpha$ cyclone with the shallow vertical structure. The tilting of vortex tubes generates both positive and negative cross-isobaric absolute vorticity and this serves only to re-organize the vorticity distribution on the isobaric surface in the mature stage.

\subsection{Dynamics-thermodynamics relationship in the meso- $\alpha$ cyclone core}

The previous section showed that our simulated vortex is maintained by the stretching term adjacent to the cyclone core (Fig. 13h). The intense stretching term is consistent roughly with the strong rainfall close to the centre (Fig. 11b), indicating the relationship between the vortex tube stretching 

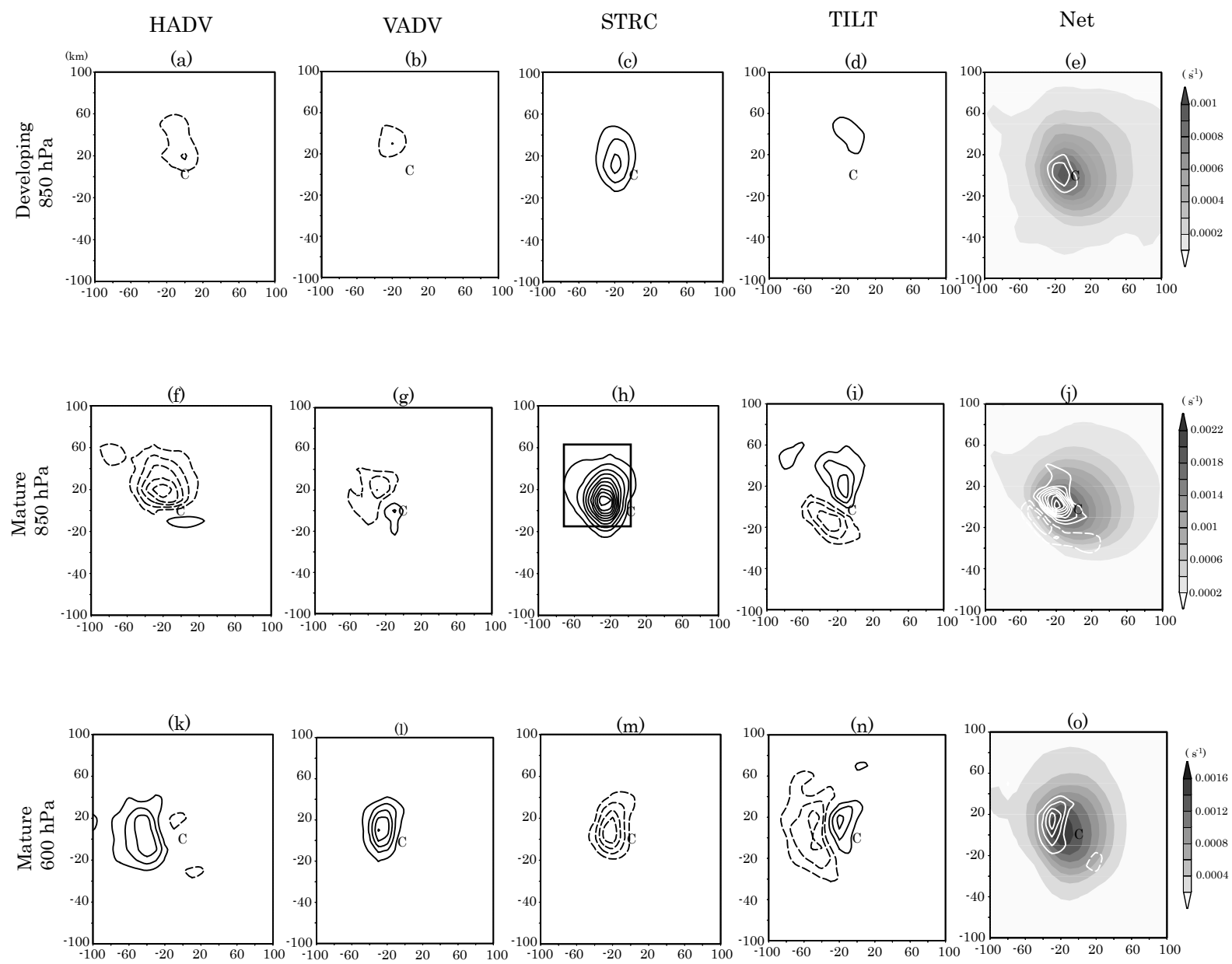

Fig. 13. The temporal mean of (a) HADV, (b) VADV, (c) STRC, (d) TILT and (e) net forcing in Eq. (1) in the developing stage at $850 \mathrm{hPa}$. The solid (dashed) lines denote positive (negative) values. The contour interval is $10^{-6} \mathrm{~s}^{-2}$. (f) $-(\mathbf{j})$ and (k)-(o) are the same as for (a) $-(\mathbf{e})$, but for the mature stage at 850 and $600 \mathrm{hPa}$, respectively. The shading shows absolute vorticity. C denotes the centre of meso- $\alpha$ cyclone.

(dynamics) and the moist cumulus convection (thermodynamics). Figure 14a shows the vertical profile of the mixing ratio of five hydrometeors used in NHM averaged over the black box in Fig. 13h in the mature stage. Basically, the rain and snow are generated mostly in the lower and upper troposphere, coinciding with the intense rainfall at the surface. This implies that the latent heat released in the formation of the rain and snow helps in the formation of the warm core by overcoming the effect of cooling due to adiabatic expansion as air parcels rise in the cyclone centre (Fig. 12d).

The vertical advection of the potential temperature, shown in Fig. 14b, cools the troposphere down. This cooling is due to the adiabatic expansion associated with the ascending motion close to the centre shown in Fig. 12c and it is present in order to compensate the diabatic heating due to the condensation/deposition/freezing processes. The upward motion around the centre, in turn, stretches the vortex tube of the meso- $\alpha$ cyclone, which contributes significantly to the cyclone maintenance (Fig. 13).

\subsection{What maintains the strong convergence in the meso- $\alpha$ cyclone?}

While the low-level vortex stretching due to isobaric convergence is mainly responsible for the intensification of the cyclone, what process is responsible for the maintenance of the convergence around the cyclone centre?

Appendix B shows that the divergence tendency equation in the frame co-moving with the cyclone centre can be written as

$$
\begin{aligned}
\frac{\partial D}{\partial t} & =-2\left(\boldsymbol{V}_{\mathrm{H}}-\boldsymbol{V}_{\mathrm{C}}\right) \cdot \nabla_{\mathrm{p}} D+\nabla_{\mathrm{p}} \cdot\left\{-\frac{\partial}{\partial p}\left[\omega\left(\boldsymbol{V}_{\mathrm{H}}-\boldsymbol{V}_{\mathrm{C}}\right)\right]\right\} \\
& -\frac{3}{2} D^{2}-2 \lambda^{2}+\frac{1}{2} \zeta_{\mathrm{a}}^{2}-\nabla_{\mathrm{p}}^{2} \Phi-\beta\left(u-u_{\mathrm{c}}\right),
\end{aligned}
$$

where $\lambda$ is the deviatoric strain (deformation less the effect of the horizontal divergence) rate of the isobaric flow field and $\beta$ is the gradient of the Coriolis parameter. The other symbols are as defined in Sect. 6.1. The right-hand side of Eq. (2) 


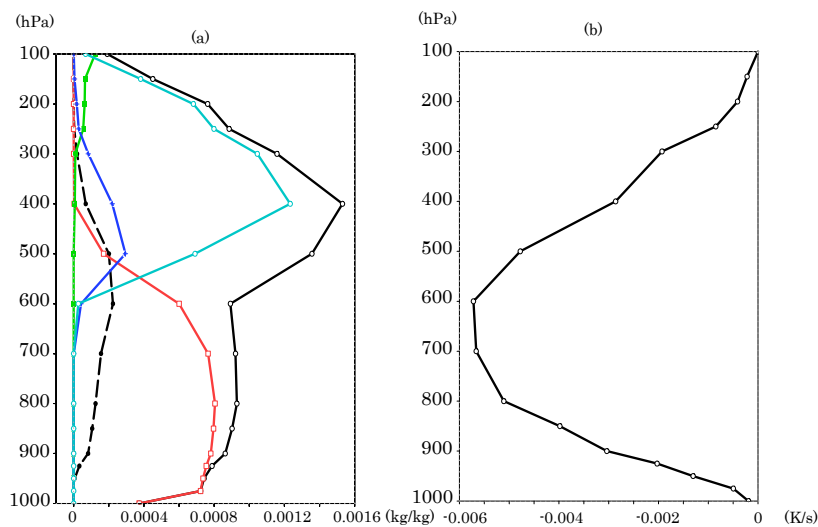

Fig. 14. The vertical profiles of (a) the mixing ratio of five hydrometeors (black dashed: cloud water, red: rain, green: cloud ice, blue: graupel, cyan: snow, and black solid: sum of the five hydrometeors) and (b) the vertical advection of the potential temperature, $-\omega(\partial \theta / \partial p)$, averaged over the black box in Fig. 13h.

comprises seven forcing terms: twice the horizontal advection of divergence (HADD), divergence of the horizontal stress due to vertical transport of momentum (VMOM), selfenhancement of convergence or self-inhibition of divergence (SELF), destruction by deviatoric strain (STRN), generation by centrifugal acceleration due to local rotation (CENT), divergence of the pressure-gradient force denoted by the Laplacian of pressure field (LAP), and beta-effect on zonal wind. The beta-effect was found to be much weaker than the other terms and will not be shown here.

Figure 15 shows the horizontal distribution of the first six forcing terms in Eq. (2) at $850 \mathrm{hPa}$ in the mature stage. Here, positive (negative) values in the figure indicate the divergence (convergence) tendency, which can be interpreted loosely as consistent with downward (upward) motion in the free atmosphere above if there is negligible vertical motion at the surface. The beta-effect is much weaker than the other terms and is not shown. CENT and LAP are very strong but have similar distributions of opposite signs (Fig. 15a and $b$ ). They represent a basic balance between the outward centrifugal and inward pressure gradient forces in a cyclone, although some residual local divergent tendency is seen (Fig. 15c) which explains the net divergent tendency (Fig. 15h). An approximate balance is also seen between HADD and VMOM (Fig. 15d and e). This means that the convergence and divergence generated by horizontal stress northwest of the vortex centre (Fig. 15e) are mostly removed by (twice) the advection from the northeasterly wind (Fig. 15d). The dipole structure of VMOM has its origin as follows: at low levels, the upward flow maximizes near $(x, y)=(-30 \mathrm{~km}, 10 \mathrm{~km})$ where the wind is northeasterly; this creates a local maximum in southwesterly stress (since the horizontal momentum is lost to mid-levels) and leads to stress convergence upwind and stress divergence downwind.
The net convergence tendency (Fig. 15h) is due mainly to SELF (Fig. 15g). However, the self-enhancement of convergence relies on the existence of net convergence in the first place. In other words, if the initial divergent field is zero, the SELF term is also zero. We suggest that deviatoric strain provides the original seed for the convergence tendency in the cyclone because STRN is the only negative-definite forcing in Eq. (2) and it is strongest where SELF and the net convergence tendency are the strongest (see Fig. 15f-h). We also note that the location of the maximum of the SELF term shows approximate agreement with the location of the hydrometeors in Fig. 14 (i.e. the box shown in Fig. 13h), indicating that the upward motion forced by the diabatic heating from the condensation/deposition/freezing of hydrometeors contributes to the strong low-level convergence for the SELF term to act as well. Therefore, the process of seeding by STRN followed by super-exponential growth by positive feedback through SELF and enhanced by the latent heat release from moist convection near the cyclone centre is how the meso- $\alpha$ cyclone is generated and maintained.

The net convergence and net divergence tendencies appear to be evenly matched in Fig. 15h, consistent with the weak net growth of the cyclone in the mature stage. In the developing stage, although each term is weaker than in the mature stage, their distributions are approximately the same and the net forcing of convergence is stronger than that of divergence, resulting in the overall growth of convergence in the cyclone (not shown). Therefore, we suggest that the Borneo vortex is spun up primarily by the low-level convergence (Sect. 6.1) which is originally forced by the deviatoric strain. The subsequent growth and maintenance of vortex is mainly due to the self-enhancement effect of convergence. The deviatoric strain is possibly induced by the confluence of synoptic cold surge and the cyclonic flow near the cyclone centre, which is the subject of the next section.

\subsection{How is the comma-shaped rainband organized in the meso- $\alpha$ cyclone?}

The northern and northeastern sweep of the comma-shaped rainband away from the cyclone centre has already been noted (Fig. 11). Here, we examine the reason for such departure from axisymmetry.

The most intense convergence is located near the cyclone centre to the northwest (Fig. 16a) with the intense commahead rainfall and strong convergence also seen in the northern and northeastern sectors, consistent with the location of tail part of the comma-shaped rainband (Fig. 11b). Conversely, a divergence zone is seen in the southern and eastern sectors adjacent to the cyclone centre. The zonal $(\partial u / \partial x)$ and meridional $(\partial v / \partial y)$ contributions to divergence (Fig. 16b and c) both show quadrupole structure within $\sim 150 \mathrm{~km}$ from the cyclone centre. Beyond $\sim 150 \mathrm{~km}$, the zonal and meridional convergence cells are stronger in the northwestern and northeastern sectors, respectively. 

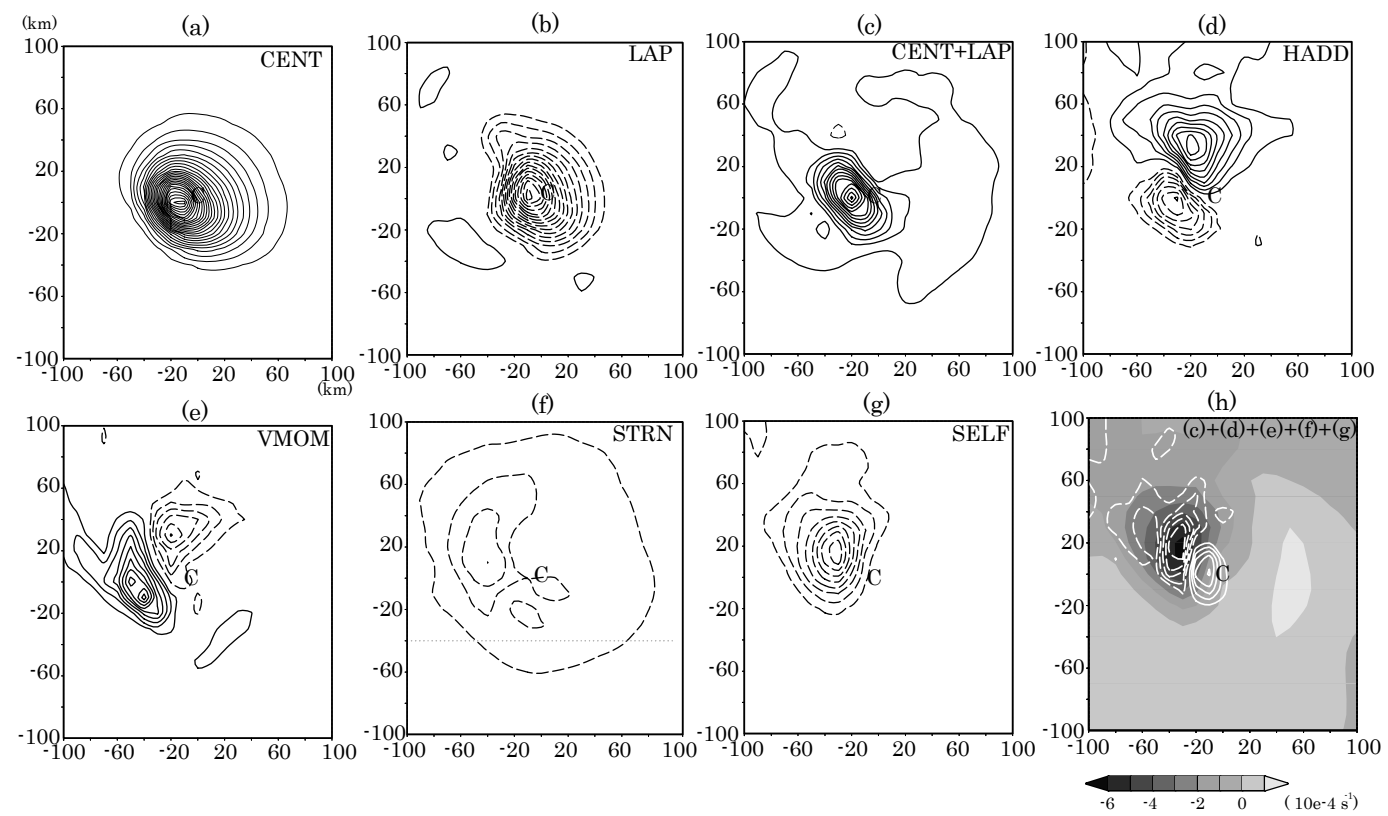

Fig. 15. The temporal mean of (a) CENT, (b) LAP, (c) CENT+LAP, (d) HADD, (e) VMOM, (f) STRN, (g) SELF, and (h) net forcing of divergence in Eq. (2) in the mature stage at $850 \mathrm{hPa}$. Solid (dashed) lines denote positive (negative) values. The contour interval is $10^{-6} \mathrm{~s}^{-2}$. The shading shows divergence. $\mathrm{C}$ denotes the centre of meso- $\alpha$ cyclone.

In a typical snapshot of the meso- $\alpha$ cyclone in the mature stage (Fig. 16d), finer structures in the form of three or four rainfall cells $10-100 \mathrm{~km}$ in size can be seen along the comma tail of the rainband. Intense cells of rainfall can be also seen at the comma head at other times in the northwestern sector near the cyclone centre (not shown).

In the comma head, a marked change of the wind direction can be identified: with reference to the red box in Fig. 16d, while the zonal component of wind west of $-100 \mathrm{~km}$ is small, it is easterly and quite intense from -100 to $0 \mathrm{~km}$ as part of the matured cyclonic flow. This change in direction results in the strong convergence (Fig. 16a-c) and intense comma-head rainfall in the northwestern sector around the centre (Fig. 15). This strong convergence at the comma head is also responsible for maintenance of the meso- $\alpha$ cyclone itself through vortex stretching as shown in Fig. 13. While the intense easterly within -100 to $0 \mathrm{~km}$ is attributed mostly to the cyclonic flow itself, the main part of wind in the outer region $(<-100 \mathrm{~km})$ seems to come from the synoptic background (larger-scale) wind rather than the meso- $\alpha$ cyclonic flow. This is because the northeasterly surge wraps itself around the cyclone core. The confluence zone of the cyclonic flow and the synoptic cold surge generates and maintains the convergence by the seeding-positive feedback process due to the STRN and SELF terms in Fig. 15, aided by the latent heat release by the intense cumulus convection that produces the rainfall at the comma head.

The above mechanism of generating strong convergence is different from frictional convergence in the atmospheric boundary layer which is one mechanism proposed to be responsible for the generation of eyewalls in tropical cyclones and typhoons (e.g. Ooyama, 1964; Yamazaki, 1983). The Coriolis acceleration is too weak near the Equator to support the Ekman pumping mechanism proposed therein. Moreover, if surface friction were important, there would be greater symmetry around the vortex as friction acts in the same way in all directions, but Fig. 16a and d show that the southern sector of the vortex is clearly divergent instead of convergent.

In the northeastern sector in Fig. 16d, confluence of oppositely directed meridional winds is mainly responsible for the meso- $\beta$-scale convergence and rainfall evidenced by the co-location of the zero meridional wind line and the comma tail of the rainband. In fact, the intensities of the convergence and rainfall in the comma tail are comparable with those in the comma head. This fact is not apparent in the temporal mean picture (Figs. 11b and 16a) because the zero meridional wind line is not stationary relative to the cyclone centre (Fig. 16e). In other words, the meso- $\alpha$-scale organization of the northeasterly surge and southeasterly cyclonic wind in the northeastern sector is the root cause of the rainband's location and the departure from axisymmetry.

Figure 17 analyses the meridionally averaged dynamic and thermodynamic profiles in the northwestern sector adjacent to the cyclone centre in the mature stage. Below $800 \mathrm{hPa}$, the sharp change of zonal wind strength is evident between -80 to $-20 \mathrm{~km}$ and strong upward flow is generated above that region (Fig. 17a). Following the upward motion, positive (indicating relatively warm and wet) anomaly 

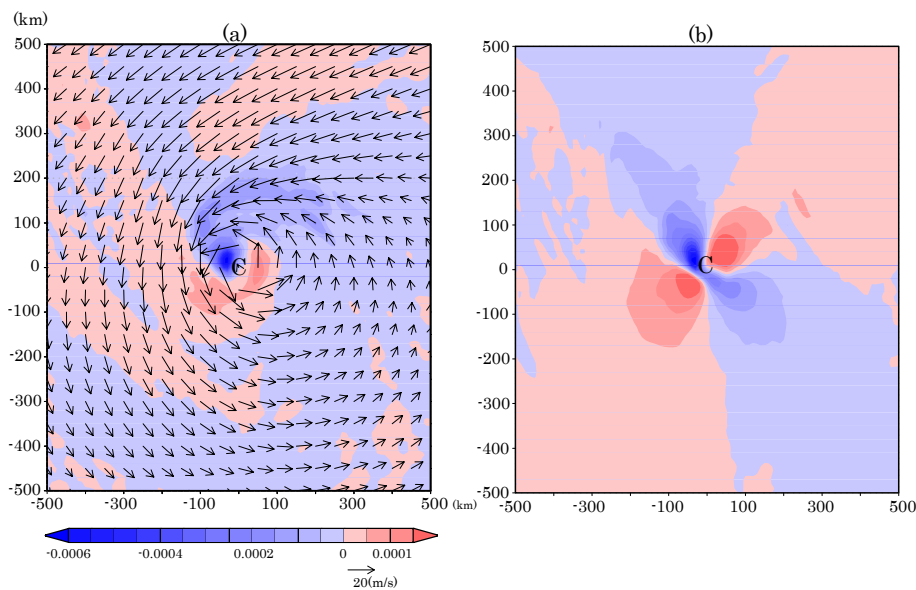
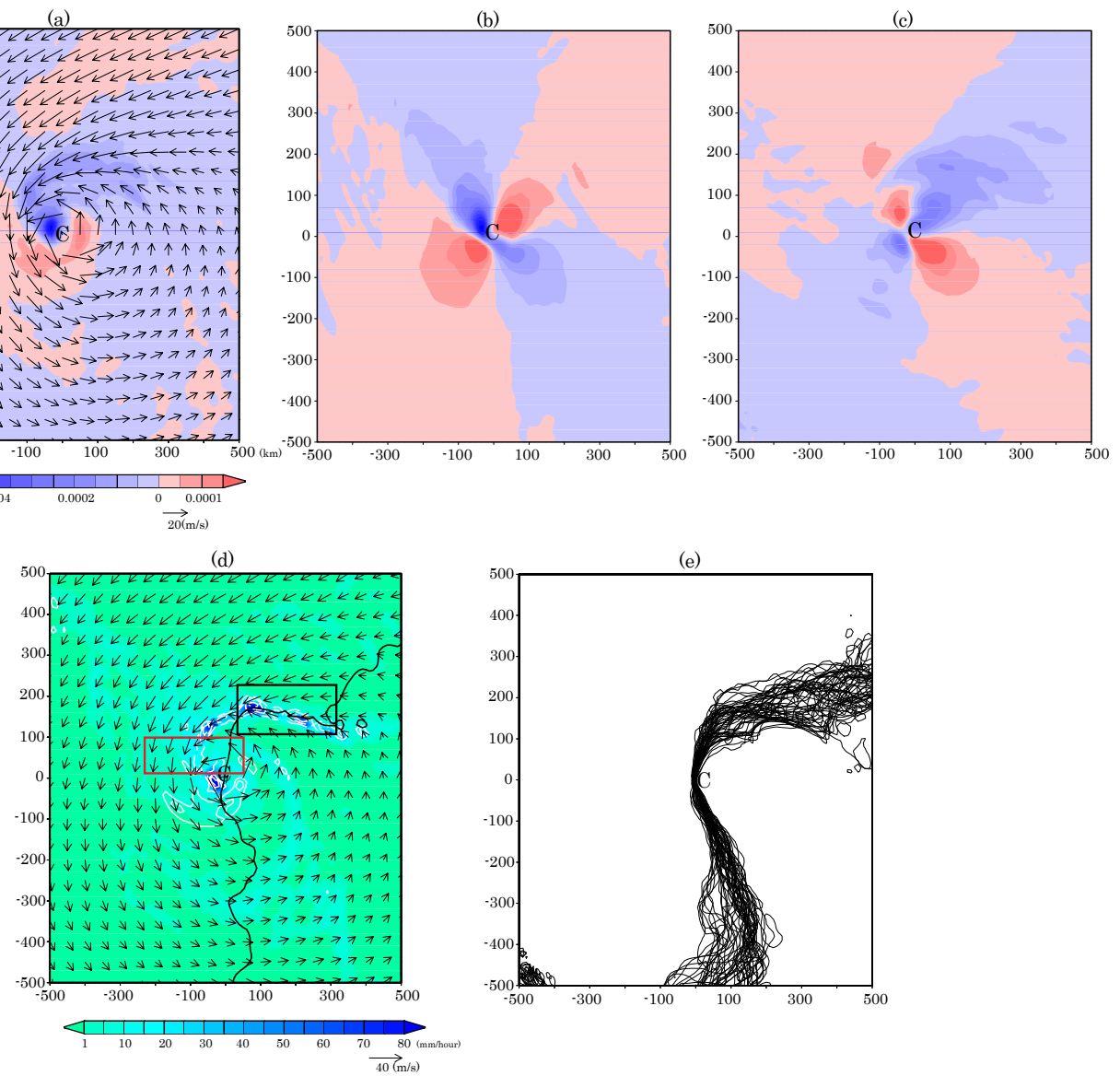

Fig. 16. (a) The temporal mean of horizontal divergence (shade) and horizontal wind (vector) in the mature stage at $850 \mathrm{hPa}$. This horizontal convergence is decomposed into (b) zonal and (c) meridional components. (d) The snapshot of horizontal divergence (white contours), hourly rainfall (shade), horizontal wind (vector), and the zero meridional wind line (black contour) at $850 \mathrm{hPa}$ at $140 \mathrm{~h}$ after the initialization. The white contours have intervals of $0.0002 \mathrm{~s}^{-1}$. Solid (dashed) lines denote positive (negative) values. (e) The zero meridional lines plotted at hourly intervals in the mature stage. $\mathrm{C}$ denotes the centre of meso- $\alpha$ cyclone. The red and black boxes in (d) are the area for pressurelongitude section in Fig. 17 and zoomed region in Fig. 19, respectively.

in equivalent potential temperature, $\theta_{\mathrm{e}}$, reaches the upper troposphere (Fig. 17b), which creates the warm core as already shown in Fig. 12c and d. Conversely, the negative (indicating relatively cool and dry) anomaly in $\theta_{\mathrm{e}}$ is found in the outer region $(<-100 \mathrm{~km})$, below $800 \mathrm{hPa}$. The negative anomaly is consistent with the northerly flow and hence weak zonal wind, indicating that the air mass in the outer region likely originates from the synoptic cold surge from the higher latitudes that has not had time to warm up or moisten yet.

With reference to Fig. $17 \mathrm{c}, 60-70 \%$ of the total rainfall around the centre is contributed by the cloud microphysics scheme in the model. So, to a large extent, the strong upward motion induces condensation and rain formation which in turn releases latent heat which has a positive feedback on the rising motion. Consequently, the warm core of the cyclone is maintained, as shown in Fig. 12d as well.

With reference to Fig. 17d, level of neutral buoyancy (LNB) has a maximum to the west of the centre. Since convective available potential energy (CAPE) is the total work done on a near-surface air parcel as it ascends to the LNB, a higher LNB means more work is done on the air parcel. Thus, CAPE follows the same pattern as LNB and it determines the pattern of rainfall parameterized by the KainFritsch cumulus scheme as well as that captured by the microphysics scheme due to explicit convection simulated in the model (Fig. 17c). The rainfall east to the cyclone centre is smaller compared to the west in spite of relatively high LNB and CAPE. This may be because divergence is found east of the centre (Fig. 15h) which indicates descending air which suppresses cumulus convection.

The location of the lowest lifting condensation level (LCL) of about $150 \mathrm{~m}$ around $-10 \mathrm{~km}$ implies additionally that the near-surface air forced upwards by low-level frontal convergence does not need to rise very high to achieve positive buoyancy. In contrast, between -200 and $-140 \mathrm{~km}$, the LCL reaches around 300 to $400 \mathrm{~m}$. This makes it easier to realize 


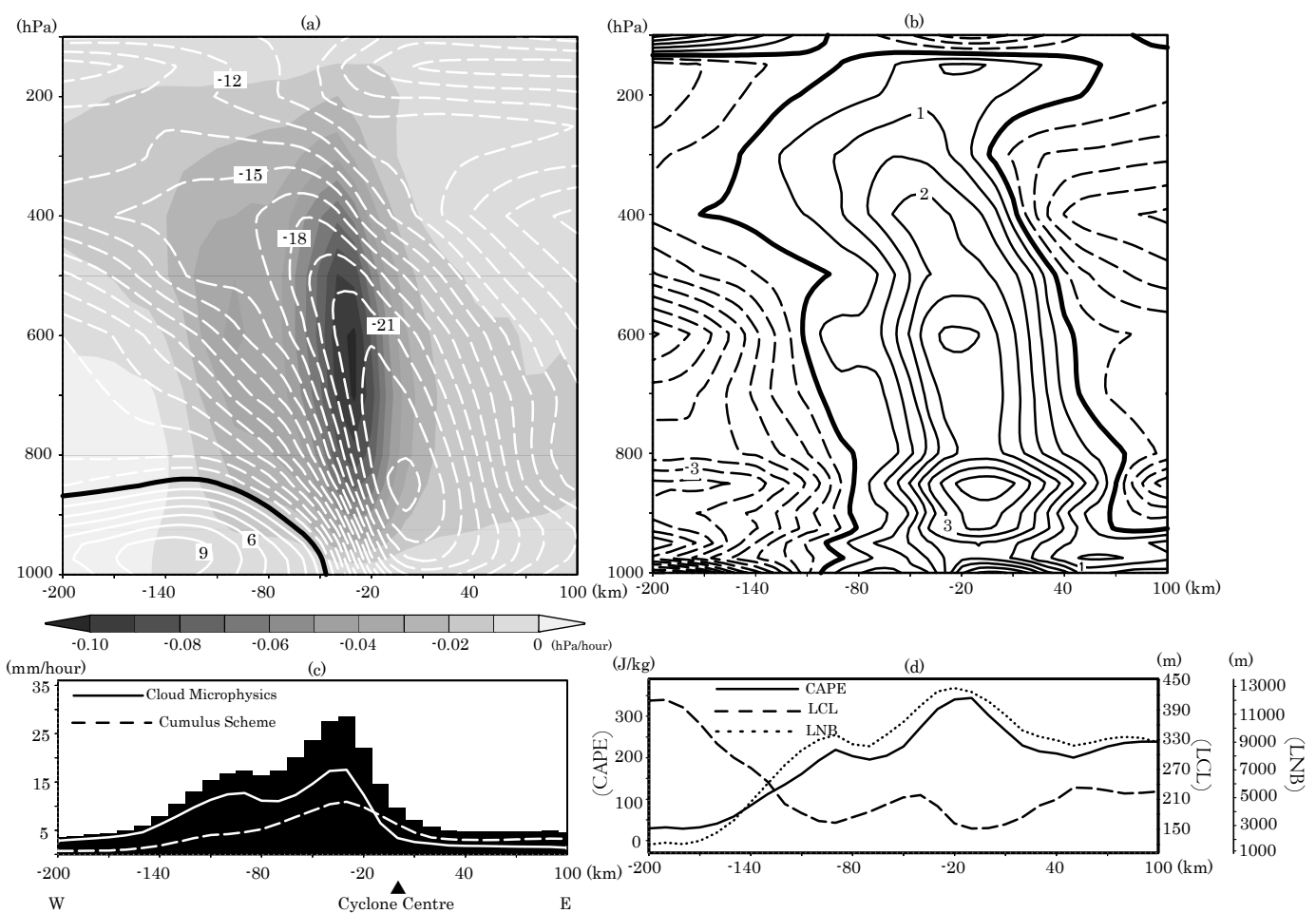

Fig. 17. The zonal sections of (a) vertical velocity, $\omega$ (shade) and zonal wind (contour), (b) deviation of equivalent potential temperature from its zonal mean (taken from -200 to $100 \mathrm{~km}$ around the cyclone centre), (c) hourly rainfall and the contributions from the cloud microphysics and cumulus schemes, and (d) convective available potential energy (CAPE, left scale), lifting condensation level (LCL, right inner scale) and level of neutral buoyancy (LNB, right outer scale). All sections are averaged meridionally between 10 to $100 \mathrm{~km}$ away from the cyclone centre shown as the red box in Fig. 16d in the mature stage. The contour intervals are $1.5 \mathrm{~m} \mathrm{~s}^{-1}$ in (a) and $0.5 \mathrm{~K}$ in (b) and solid (dashed) lines denote positive (negative) values. The zero contours in (a) and (b) are marked as thick black lines. The positive (negative) displacement in the abscissa refers to distance east (west) of the cyclone centre at all times.

the strong conditional instability around the centre compared to the far western sector, especially for the explicitly resolved convection. Thus, it is not surprising that the microphysics rain formation is overwhelmingly intense at the front.

Regarding the comma-tail rainfall, Fig. 18 analyses the dynamic and thermodynamic profiles across the meridional confluence line in the mature stage. It shows similar features to those in the northeastern sector: the confluence of southerly and northerly wind is evident in the lower troposphere (Fig. 18a). Moreover, higher (lower) $\theta_{\mathrm{e}}$ associated with warmer and more humid (cooler and drier) conditions is found south (north) of the confluence line (Fig. 18b). In fact, the frontal nature of the confluence line is clearly marked by a narrow zone of sharp $\theta_{\mathrm{e}}$ gradient, indicating that southerly (northerly) air mass originates from the equatorial South China Sea (continental Asia); $70-80 \%$ of the total rainfall at the confluence front is contributed by the cloud microphysics scheme in the model (Fig. 18c). The peak rainfall from the cumulus parameterization is less pronounced at the confluence front. Similar to the comma-head rainfall, the strong upward motion due to the low-level frontal confluence induces most of the condensation and rain formation in the comma tail. Such a mechanism of rain formation is similar to that in the Meiyu-Baiu front over the western North Pacific Ocean (e.g. Moteki et al., 2004a, b), although the spatio-temporal scale and the underlying frontal dynamics are very different. The thermodynamics indicators LNB, CAPE and LCL show similar patterns to those in Fig. 17d and have extrema over the confluence front.

The diagnostics in Figs. 17 and 18 actually reflect the same underlying three-dimensional structure of the Borneo vortex where the comma-shaped rainband is basically caused by the confluence of the background monsoonal cold surge and the meso- $\alpha$ cyclonic flow everywhere in the northern sector from the comma head to the comma tail. The model simulation has revealed the mesoscale details of how the moist convection may be maintained in some Borneo vortices. The relatively cold and dry monsoon surge wraps itself around the cyclonic core in the boundary layer, slowly moistening and warming up due to the surface latent and sensible heat fluxes. The air gradually loses its thermodynamic signature and transforms into the warm and moist equatorial air circulating around the cyclone with the South China Sea as the source of moist static energy. When the warm cyclonic air meets with the incoming 

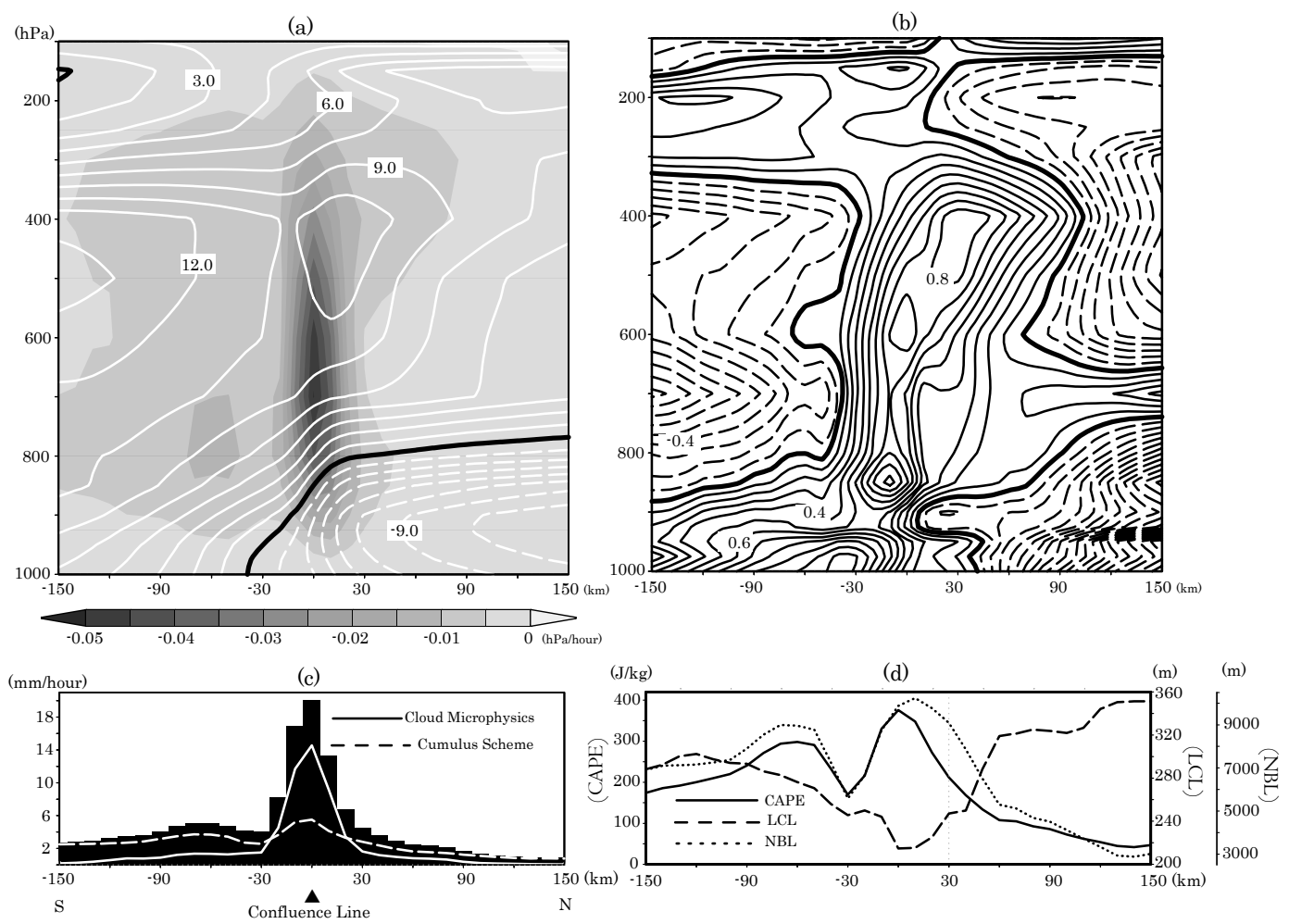

Fig. 18. As in Fig. 17, but for the meridional section. All sections are taken across and averaged along the confluence lines (zero meridional lines in Fig. 16e) for $x$ between 100 and $300 \mathrm{~km}$ in the mature stage and then temporally averaged. The convention of contours are also the same as in Fig. 17, except for $0.1 \mathrm{~K}$ for (b). The positive (negative) displacement in the abscissa refers to distance north (south) of the confluence line at all time.

cold surge in the northern sector of the Borneo vortex, it is lifted up in a frontal collision. With the help of lowered LCL and enhanced CAPE, much condensation and convective precipitation at the front gives rise to the formation of a comma-shaped rainband in the northern sector. (The sharp front separating the monsoon surge and the cyclonic air is not observed in the SS composite of the reanalysis data partly because the low resolution of the global model used to assimilate the data cannot capture mesoscale frontal dynamics, partly because closed-circulation vortices do not always form during SS and when they do, they are of different size, shape and at different locations.)

Now, what maintains the meso- $\beta$-scale convergence and hence the rainband at the confluence front? The divergence tendency diagnostic in Eq. (2) for the confluence front along the comma tail is shown in Fig. 19. CENT is not significant implying that local rotation is not an important dynamical factor at the meso- $\beta$ scale (Fig. 19a). The contribution of LAP is relatively weak and its distribution is similar to that of the much stronger VMOM (Fig. 19b and d). The latter is because of the alignment between the pressure-gradient force and the horizontal stress. An approximate balance between HADD (Fig. 19c) and (VMOM+LAP) holds at the meso$\beta$ scale. Along the confluence front, the net convergence tendency (Fig. 19g) comes mainly from SELF (Fig. 19f). But again, the negative-definite STRN which maximizes along the front (Fig. 19e) is likely to be the origin of the convergence tendency. Therefore, the convergence along the confluence front (Fig. 19h) is forced originally by the deviatoric strain inherent in the confluence of the northeasterly surge and the southwesterly cyclonic wind in the Borneo vortex, and this is subsequently intensified by nonlinear selfenhancement dynamics.

\section{Concluding remarks}

We have investigated the Borneo vortex and mesoscale convective rainband associated with the monsoon cold surge over the equatorial South China Sea.

The composite analysis based on Cold Surge Index revealed that the strong cold surge transports absolute vorticity and water vapour from the higher tropical latitudes to the equatorial region. The daily rainfall over the South China Sea is enhanced significantly when the strong cold surge occurs and its distribution matches roughly with vorticity and water vapour flux convergence in the lower troposphere. The diurnal cycle of rainfall showed that rainfall over the South China Sea is intensified over the whole day, whereas rainfall over 

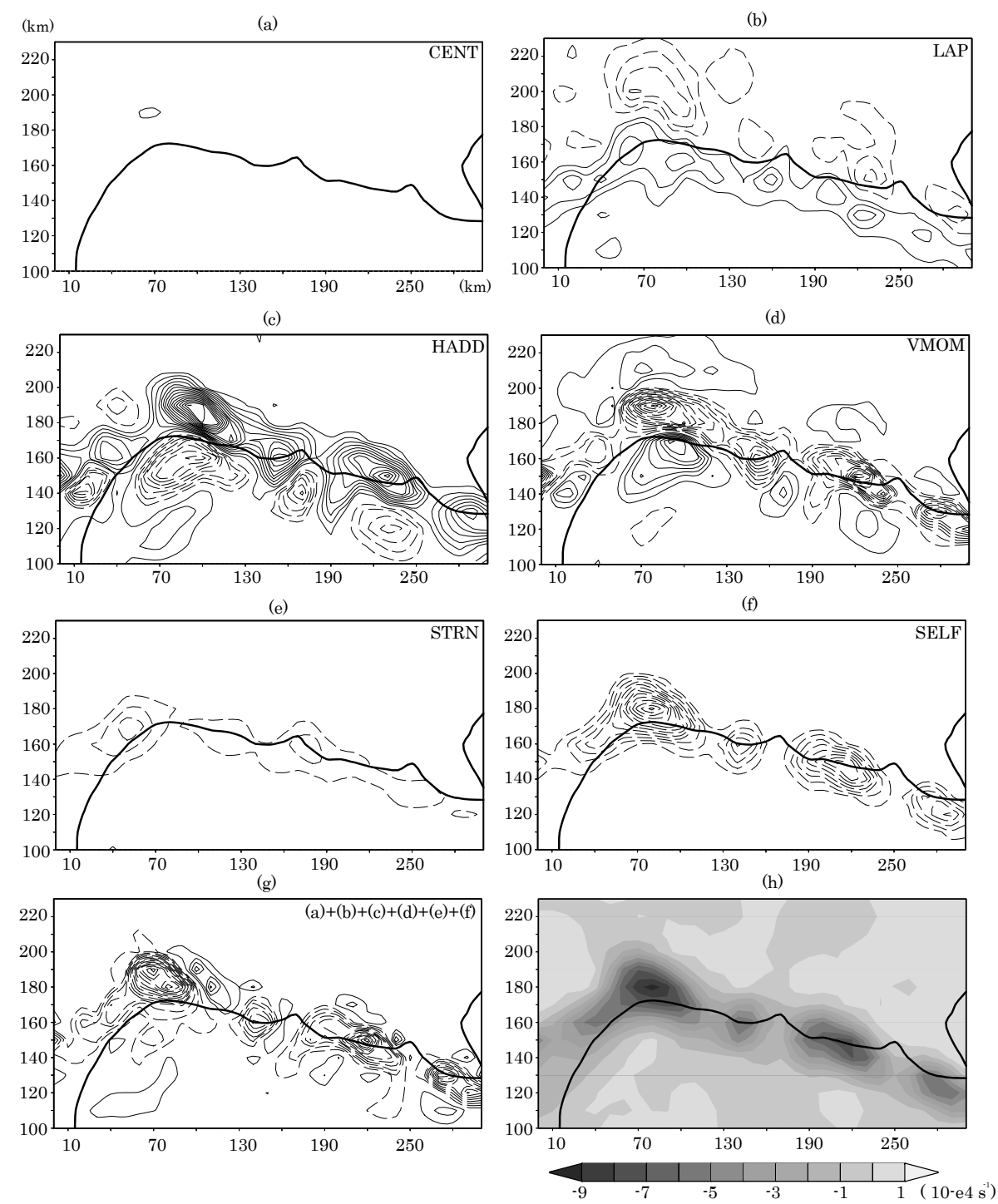

Fig. 19. Snapshot of the divergence tendency budget (see Eq. 2) along the meridional confluence front in the northeastern part of the meso- $\alpha$ cyclone for (a) CENT, (b) LAP, (c) HADD, (d) VMOM, (e) STRN, (f) SELF and (g) net forcing at $850 \mathrm{hPa}$ at $140 \mathrm{~h}$ after the initialization; (h) is divergence at same level and time. The contouring convention is the same as in Fig. 15. The thick black contour is the zero meridional wind line. This region is black box in Fig. 16d.

the Java Sea is reinforced only at night-morning time. This is consistent with the fact that the rainfall over the Java Sea is mainly due to the interaction of the seaward land breeze and the landward monsoon wind whereas the rainfall over the equatorial South China Sea is organized by larger-scale dynamics. Other composite analyses of the Borneo vortex show intense rainfall and convergence in the north and northeast sectors of the Borneo vortex but shed little light on mesoscale structure or processes.

The semi-idealized experiment using NHM has shown well-organized features of the Borneo vortex and the comma-shaped rainband over the equatorial South China Sea associated with cold surges. Diagnostics of absolute vorticity tendency revealed that vortex stretching due to intense low-level convergence is mostly responsible for growth/maintenance of the cyclone. The divergence tendency budget analysis suggested that the strong convergence around the meso- $\alpha$ cyclone core is caused by the deviatoric strain and maintained by self-enhancement.

A comma-shaped rainband is seen sweeping northwest and northeast from the centre of the meso- $\alpha$ cyclone with clusters of meso- $\beta$-scale rainfall cells. In the northwestern sector, the confluence of the intense easterly due to the cyclone itself and weak easterly or westerly corresponding to the background cold surge generates strong low-level convergence and intense rainfall at the comma head. This 
convergence is responsible for the growth/maintenance of the meso- $\alpha$ cyclone system shown by dynamical diagnoses. In the northeastern sector, cyclonic southeasterly flow (relatively warm and wet) collides with the northeasterly surge (relatively cool and dry) in the northeastern sector of the meso- $\alpha$ cyclone. The frontal confluence generates strong rising motion which is associated with much condensation and rain formation in the comma tail of the rainband. Thermodynamic factors such as convective available potential energy and lifting condensation level show consistency with enhanced convective propensity at the confluence zones. The divergence tendency budget analysis along the confluence front indicates once more that the deviatoric strain inherent in the confluent wind field spawns the convergence at the confluence front and self-enhancement dynamics greatly intensifies the convergence maintaining the rainband.

Our results in this paper reveal new detailed features of the meso- $\beta$-scale structure of the Borneo vortex in the organization of the comma-shaped rainband. The dynamical mechanisms for growth and maintenance of the vortex and the confluence front are also clarified. We suggest that the comma-shaped rainband (at meso- $\beta$ scale) in the meso- $\alpha$ cyclone is generated by the confluence of the background monsoonal cold surges (at synoptic scale) and the cyclonic flow (at meso- $\alpha$ scale).

As a possible future investigation, mesoscale observations of Borneo vortices would help to elucidate how realistic our simulation results are. Moreover, because the resolution of our experiment is only $10 \mathrm{~km}$, we have not explored the meso- $\gamma$-scale $(1-10 \mathrm{~km})$ dynamics in the convective towers of the rainband in the Borneo vortex. Advanced numerical experiment with finer resolution would seem desirable.

Acknowledgements. The authors would like to show their appreciation to two anonymous reviewers for their constructive reviewing comments and suggestions. The authors are grateful to K. Saito and S. Hayashi of the Meteorological Research Institute, Japan Meteorological Agency, M. Sawada of Tohoku University, and M. Inatsu of Hokkaido University, for their advice in running NHM. The authors would also like to express appreciation to K. K. W. Cheung of Macquarie University and S. Otsuka of Kyoto University for meaningful discussions about the Borneo vortex. This work comprises in part Earth Observatory of Singapore contribution 69 .

Edited by: P. Haynes

\section{References}

Asai, T.: Meso-scale features of heavy snowfalls in Japan Sea coastal region of Japan, Tenki, 35, 156-161, 1988.

Braesicke, P., Ooi, S. H., and Samah, A. A.: Propeties of strong offshore Borneo vortices: a composite analysis of flow pattern and composition as captured by ERA-Interim, Atmos. Sci. Lett., 13, 128-132, doi:10.1002/asl.372, 2012.
Chambers, C. R. S. and Li, T.: Simulation of formation of a nearequatorial typhoon Vamei (2001), Meteorol. Atmos. Phys., 98, 67-80, doi:10.1007/s00703-006-0229-0, 2007.

Chang, C.-P., Liu, C.-H., and Kuo, H.-C.: Typhoon Vamei: An equatorial tropical cyclone Formation, Geophys. Res. Lett., 30, 1150, doi:10.1029/2002GL016365, 2003.

Chang, C.-P., Harr, P. A., and Chen, H.-J.: Synoptic disturbances over the equatorial South China Sea and western Maritime Continent during boreal winter, Mon. Weather Rev., 133, 489-503, doi:10.1175/MWR-2868.1, 2005.

Chen, G. T. J., Gerish, T. E., and Chang, C. -P.: Structure variations of the synoptic-scale cyclonic disturbances near Borneo during WMONEX period, Pap. Meteorol. Res., 9, 117-135, 1986.

Chen, J. M., Chang, C.-P., and Li, T.: Annual cycle of the South China sea surface temperature using the NCEP/NCAR reanalysis, J. Meteorol. Soc. Jpn., 81, 879884, doi:10.2151/jmsj.81.879, 2003.

Chen, T.-C., Tsay, J.-D., Yen, M.-C., and Matsumoto, J.: Interannual variation of the late fall in central Vietnam, J. Climate, 25, 392413, doi:10.1175/JCLI-D-11-00068.1, 2012.

Estoque, M. A.: The sea breeze as a function of the prevailing synoptic situation, J. Atmos. Sci., 19, 244-250, doi:10.1175/15200469(1962)019<0244:TSBAAF>2.0.CO;2, 1962.

Frank, W. M.: The structure and energetics of the tropical cyclone I: Storm structure, Mon. Weather Rev., 105, 1119-1135, doi:10.1175/1520-0493(1977)105<1119:TSAEOT>2.0.CO;2, 1977.

Hadi, T. W., Horinouchi, T., Tsuda, T., Hashiguchi, H., and Fukao. S.: Sea-breeze circulation over Jakarta, Indonesia: A climatology based on boundary layer radar observations. Mon. Weather Rev., 130, 2153-2166, doi:10.1175/15200493(2002)130<2153:SBCOJI>2.0.CO;2, 2002.

Hattori, M., Mori, S., and Matsumoto, J.: The Cross-Equatorial Northerly Surge over the Maritime Continent and Its Relationship to Precipitation Patterns, J. Meteorol. Soc. Jpn., 89A, 27-47, doi:10.2151/jmsj.2011-A02, 2011.

Hayashi, S., Aranami, K., and Saito, K.: Statistical Verification of Short Term NWP by NHM and WRF-ARW with $20 \mathrm{~km}$ Horizontal Resolution around Japan and Southeast Asia, SOLA, 4, 133-136, doi:10.2151/sola.2008-034, 2008.

Holland, G. J. and Merrill, R. T.: On the dynamics of tropical cyclone structural-changes, Q. J. Roy. Meteorol. Soc., 110, 723745, doi:10.1002/qj.49711046510, 1984.

Hong, C.-C., Hsu, H.-H., and Chia, H.-H.: A Study of East Asian Cold Surges during the 2004/05 Winter: Impact of East Asian Jet Stream and Subtropical Upper-Level Rossby Wave Trains, Terr. Atmos. Ocean. Sci., 20, 333-343, doi:10.3319/TAO.2008.02.04.01(A), 2009.

Hubert, L. F., Kruger, A. F., and Winston, J. S.: Double Intertropical Convergence Zone-Fact and Fiction?, J. Atmos. Sci., 26, 771-773, doi:10.1175/15200469(1969)026<0771:TDICZF>2.0.CO;2, 1969.

Huffman, G. J., Adler, R. F., Bolvin, D. T., Gu, G. J., Nelkin, E. J., Bowman, K. P., Hong, Y., Stocker, E. F., and Wolff, D. B.: The TRMM multisatellite precipitation analysis (TMPA): Quasiglobal, multiyear, combined-sensor precipitation estimates at fine scales, J. Hydrometeorol., 8, 38-55, doi:10.1175/JHM560.1, 2007. 
Ikawa, M. and Saito, K.: Description of a non-hydrostatic model developed at the Forecast Research Department of the MRI, MRI Tech. Rep. 28, Meteorological Research Institute, Tsukuba, Ibaraki, Japan, p. 238, 1991.

Johnson, R. H. and Houze Jr., R. A.: Precipitating cloud systems of the Asian monsoon, in: Monsoon Meteorology, edited by: Chang, C.-P. and Krishnamurti, T. N., Oxford University Press, 298-353, 1987.

Joseph, B., Bhatt, B. C., Koh, T.-Y., and Chen, S.: Sea breeze simulation over the Malay Peninsula in an intermonsoon period, J. Geophys. Res., 113, D20122, doi:10.1029/2008JD010319, 2008.

Joung, C. H. and Hitchman, M. H.: On the role of successive downstream development in East Asian polar air outbreaks, Mon. Weather Rev., 110, 1224-1237, doi:10.1175/15200493(1982)110<1224:OTROSD>2.0.CO;2, 1982.

Juneng, L. and Tangang, F. T.: Long-term trends of winter monsoon synoptic circulations over the maritime continent: 1962-2007, Atmos. Sci. Lett., 11, 199-203, doi:10.1002/asl.272, 2010.

Kain, J. S.: The Kain-Fritsch convective parameterization: An update, J. Appl. Meteorol., 43, 170-181, doi:10.1175/15200450(2004)043<0170:TKCPAU>2.0.CO;2, 2004.

Kawashima, M. and Fujiyoshi, Y.: Shear instability wave along a snowband: Instability structure, evolution, and energetic derived from dual-Doppler radar data, J. Atmos. Sci., 62, 351-370, doi:10.1175/JAS-3392.1, 2005.

Koseki, S., Koh, T.-Y., and Teo, C.-K.: Effects of the cold tongue in the South China Sea on the monsoon, diurnal cycle and rainfall in the Maritime Continent, Q. J. Roy. Meteorol. Soc., 139, 15661582, doi:10.1029/qj2025, 2013.

Kumagai, Y.: Improvement of the land surface processes in JMANHM, CAS/JSC WGNE Res. Activ. Atmos. Ocean. Modell., 34, 0419-0420, 2004.

Lau, K.-M. and Chang, C.-P.: Planetary scale aspects of winter monsoon and Teleconnections, in: Monsoon Meteorology, edited by: Chang, C.-P. and Krishnamurti, T. N., Oxford University Press, 161-202, 1987.

Lim, H. and Chang, C.-P.: A Theory of Mid-latitude Forcing of Tropical Motions during Winter Monsoon, J. Atmos. Sci., 38, 2377-2392, doi:10.1175/15200469(1981)038<2377:ATFMFO>2.0.CO;2, 1981.

Lu, M.-M., and Chang, C.-P.: Unusual Late-Season Asian Cold Surges during the 2005 Asian Winter Monsoon: Roles of Atlantic Blocking and the Central Asian Anticyclone, J. Climate, 22, 5205-5217, doi:10.1175/2009JCLI2935.1, 2009.

Mak, M. K. and Walsh, J. E.: On the Relative Intensities of Sea and Land Breezes, J. Atmos. Sci., 33, 242-251, doi:10.1175/15200469(1976)033<0242:OTRIOS>2.0.CO;2, 1976.

Moteki, Q, Uyeda, H., Maesaka, T., Shinoda, T., Yoshizaki, M., and Kato, T.: Structure and development of two merged rainbands observed over the East China Sea during X-BAIU-99 part I: Meso-beta-scale structure and development processes, J. Meteorol. Soc. Jpn., 82, 19-44, doi:10.2151/jmsj.82.19, 2004a.

Moteki, Q, Uyeda, H., Maesaka, T., Shinoda, T., Yoshizaki, M., and Kato, T.: Structure and development of two merged rainbands observed over the East China Sea during X-BAIU-99 part II: Meso-alpha-scale structure and build-up processes of convergence in the Baiu frontal region, J. Meteorol. Soc. Jpn., 82, 4565, doi:10.2151/jmsj.82.45, 2004b.
Nagata, M.: On the structure of a convergent cloud band over the Japan Sea in winter: A prediction experiment, J. Meteorol. Soc. Jpn., 65, 871-883, 1987.

Nagata, M.: Meso-beta-scale vortices developing along the JapanSea polar-airmass convergence zone (JPCZ) cloud band: Numerical simulation, J. Meteorol. Soc. Jpn., 71, 43-57, 1993.

Nakanishi, M.: Improvement of the Mellor-Yamada turbulence closure model based onlarge-eddy simulation data, Bound.-Lay. Meteorol., 99, 349-378, doi:10.1023/A:1018915827400, 2001.

Nakanishi, M. and Niino, H.: An improved Mellor-Yamada level-3 model with condensation physics: Its design and verification, Bound.-Lay. Meteorol., 112, 1-31, doi:10.1023/B:BOUN.0000020164.04146.98, 2004.

Nakanishi, M. and Niino, H.: An improved Mellor-Yamada level-3 model: Its numerical stability and application to a regional prediction of advection fog, Bound.-Lay. Meteorol., 119, 397-407, doi:10.1007/s10546-005-9030-8, 2006.

Onogi, K., Tslttsui, J., Koide, H., Sakamoto, M., Kobayashi, S., Hatsushika, H., Matsumoto, T., Yamazaki, N., Kamahori, H., Takahashi, K., Kadokura, S., Wada, K., Kato, K., Oyama, R., Ose, T., Mannoji, N., and Taira, R.: The JRA-25 Reanalysis, J. Meteorol. Soc. Jpn., 85, 369-432, doi:10.2151/jmsj.85.369, 2007.

Ooyama, K.: A dynamical model for the study of tropical cyclone development, Geofisica Int., 4, 187-198, 1964.

Qian, J. H., Robertson, A. W., and Moron, V.: Interactions among ENSO, the Monsoon, and Diurnal Cycle in Rainfall Variability over Java, Indonesia, J. Atmos. Sci., 67, 3509-3524, doi:10.1175/2010JAS3348.1, 2010.

Saito, K., Fujita, T., Yamada, Y., Ishida, J. I., Kumagai, Y., Aranami, K., Ohmori, S., Nagasawa, R., Kumagai, S., Muroi, C., Kato, T., Eito, H., and Yamazaki, Y.: The operational JMA nonhydrostatic mesoscale model, Mon. Weather Rev., 134, 1266-1298, doi:10.1175/MWR3120.1, 2006.

Saito, K., Ishida, J. I., Aranami, K., Hara, T., Segawa, T., Narita, M., and Honda, Y.: Nonhydrostatic atmospheric models and operational development at JMA, J. Meteorol. Soc. Jpn., 85B, 271304, doi:10.2151/jmsj.85B.271, 2007.

Seko, H., Hayashi, S., Kunii, M., and Saito, K.: Structure of the Regional Heavy Rainfall System that Occurred in Mumbai, India, on 26 July 2005, SOLA, 4, 129-132, doi:10.2151/sola.2008-033, 2008.

Takaya, K. and Nakamura, H.: Mechanisms of intraseasonal amplification of the cold Siberian high, J. Atmos. Sci., 62, 4423-4440, doi:10.1175/JAS3629.1, 2005.

Tangang, F. T., Juneng, L., Salimun, E., Vinayachandran, P. N., Seng, Y. K., Reason, C. J. C., Behera, S. K., and Yasunari, T.: On the roles of the northeast cold surge, the Borneo vortex, the Madden-Julian Oscillation, and the Indian Ocean Dipole during the extreme 2006/2007 flood in southern Peninsular Malaysia, Geophys. Res. Lett., 35, L14S07, doi:10.1029/2008GL033429, 2008.

Teo, C.-K., Koh, T.-Y., Lo, J. C. F., and Bhatt, B. C.: Principal component analysis of observed and modeled diurnal rainfall in the Maritime Continent, J. Climate, 24, 4662-4675, doi:10.1175/2011JCLI4047.1, 2011.

Tomita, T. and Yasunari, T.: Role of the northeast winter monsoon on the biennial oscillation of the ENSO/monsoon system, J. Meteorol. Soc. Jpn., 74, 399-413, 1996. 
Trilaksono, N. J., Otsuka, S., and Yoden, S.: A Time-Lagged Ensemble Simulation on the Modulation of Precipitation over West Java in January-February 2007, Mon. Weather Rev., 140, 601616, doi:10.1175/MWR-D-11-00094.1, 2012.

Tsuboki, K. and Asai, T.: The multi-scale structure and development mechanism of mesoscale cyclones over the sea of Japan in winter, J. Meteorol. Soc. Jpn., 82, 597-621, doi:10.2151/jmsj.2004.597, 2004.
Wangwongchai, A., Zhao, S. X., and Zeng, Q. C.: A case study on a strong tropical disturbance and record heavy rainfall in Hat Yai, Thailand during the winter monsoon, Adv. Atmos. Sci., 22, 436450, doi:10.1007/BF02918757, 2005.

Yamazaki, M.: A future study of the tropical cyclone without parameterizing the effects of cumulus convection, Papers Meteor. Geophys., 34, 221-260, 1983. 


\section{Appendix A}

\section{Definition of the centre of the meso- $\alpha$ cyclone}

The centre of the Borneo vortex and meso- $\alpha$ cyclone in Sects. 4 and 5 is defined in this section. First, the mean lowlevel wind $\left(U_{i, j}, V_{i, j}\right)$ over a centred $3 \times 3$-point moving gird is defined as

$U_{i, j}=\frac{1}{9} \sum_{k=-1}^{1} \sum_{l=-1}^{1}\left(u_{i+k, j+l}\right)$,

$V_{i, j}=\frac{1}{9} \sum_{k=-1}^{1} \sum_{l=-1}^{1}\left(v_{i+k, j+l}\right)$, where $u_{i, j,}$ and $v_{i, j}$ are average zonal and meridional winds from 800 to $950 \mathrm{hPa}$. Here, $i$ and $j$ are the zonal and meridional indices of a grid point, respectively. The magnitude of the mean wind is thus

$U_{i, j}=\sqrt{U_{i, j}^{2}+V_{i, j}^{2}}$.

We define the location of the minimum $U_{i, j}$ in the cyclone as the cyclone centre at every hour, because the cyclonic flow in the immediate neighbourhood of the centre nearly cancels out, leaving sometimes a weak background wind. 


\section{Appendix B}

\section{Deviation of the tendency equations for absolute vorticity and divergence}

The horizontal momentum equations in the frame co-moving with the cyclone centre are

$$
\begin{aligned}
& \frac{\partial u}{\partial t}+\left(u-u_{\mathrm{c}}\right) \frac{\partial u}{\partial x}+\left(v-v_{\mathrm{c}}\right) \frac{\partial u}{\partial y}+\omega \frac{\partial u}{\partial p}=f\left(v-v_{\mathrm{c}}\right) \\
& \quad+\Omega_{z}^{2} \Delta x-\frac{\partial \Phi}{\partial x}-A_{x}, \\
& \frac{\partial v}{\partial t}+\left(u-u_{\mathrm{c}}\right) \frac{\partial v}{\partial x}+\left(v-v_{\mathrm{c}}\right) \frac{\partial v}{\partial y}+\omega \frac{\partial v}{\partial p}=-f\left(u-u_{\mathrm{c}}\right) \\
& \quad+\Omega_{z}^{2} \Delta y-\frac{\partial \Phi}{\partial y}-A_{y},
\end{aligned}
$$

where for convenience, beta-plane dynamics is assumed. Cartesian coordinates $(x, y) \equiv\left(x_{0}+\Delta x, y_{0}+\Delta y\right)$ such that $\Delta x \ll x_{0}, \Delta y \ll y_{0}$ represent displacements in the east-west and north-south directions respectively. $u$ and $v$ are zonal and meridional winds respectively; $\omega \equiv \mathrm{D} p / \mathrm{D} t$ is the crossisobaric velocity in $p$ coordinate where $p$ denotes pressure. $\Phi$ is the geopotential. $f \equiv f\left(y_{0}\right)+\beta \Delta y$ is the latitudedependent Coriolis parameter, where $f_{0}$ and $\beta$ take the constant values characteristic of the reference latitude at $y_{0}$. $\left(\Omega_{z}^{2} \Delta x, \Omega_{z}^{2} \Delta y\right)$ is the $f$ plane representation of the centrifugal acceleration, where $\Omega_{z} \equiv \frac{1}{2} f\left(y_{0}\right)$ is the Earth's rotation rate in the local vertical direction at $y_{0}$. (The betaplane representation of centrifugal acceleration is not necessary or consistent here as $O\left(\Delta x^{2}, \Delta x \Delta y, \Delta y^{2}\right)$ terms are neglected.) $\boldsymbol{V}_{\mathrm{C}} \equiv\left(u_{\mathrm{c}}, v_{\mathrm{c}}\right)$ and $\boldsymbol{A}_{\mathrm{C}} \equiv\left(A_{x}, A_{y}\right)$ are the velocity and acceleration in the motion of the cyclone centre in Fig. 101 and so are functions of time $t$ only.

Taking the difference of the isobaric derivatives,

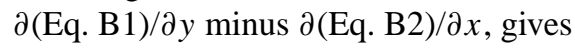

$$
\begin{aligned}
\frac{\partial \zeta}{\partial t} & =-\left(\boldsymbol{V}_{\mathrm{H}}-\boldsymbol{V}_{\mathrm{C}}\right) \cdot \nabla_{\mathrm{p}} \zeta-\omega \frac{\partial \zeta}{\partial p}-\zeta D-\left(\frac{\partial \omega}{\partial x} \frac{\partial v}{\partial p}-\frac{\partial \omega}{\partial y} \frac{\partial u}{\partial p}\right) \\
& -f D-\beta\left(v-v_{\mathrm{c}}\right),
\end{aligned}
$$

where $\zeta \equiv v_{x}-u_{y}$ is the relative vorticity on an isobaric surface. Thus, the tendency equation for absolute vorticity on an isobaric surface $\zeta_{\mathrm{a}} \equiv f+\zeta$ can be derived as in Eq. (1).

Taking the sum of the isobaric derivatives $\partial($ Eq. B1)/ $\partial x$ and $\partial($ Eq. B2)/ $/ \partial y$ gives

$$
\begin{aligned}
\frac{\partial D}{\partial t} & =-\left(\boldsymbol{V}_{\mathrm{H}}-\boldsymbol{V}_{\mathrm{C}}\right) \cdot \nabla_{\mathrm{p}} D-\omega \frac{\partial D}{\partial p}-\nabla_{\mathrm{p}} \omega \cdot \frac{\partial\left(\boldsymbol{V}_{\mathrm{H}}-\boldsymbol{V}_{\mathrm{C}}\right)}{\partial p} \\
& -D^{2}+2 J(u, v)+f \zeta+\frac{1}{2} f^{2}-\nabla_{\mathrm{p}}^{2} \Phi-\beta\left(u-u_{\mathrm{c}}\right),
\end{aligned}
$$

where $D \equiv \partial u / \partial x+\partial v / \partial y$ is the isobaric divergence and $J(u, v) \equiv u_{x} v_{y}-v_{x} u_{y}$ is the Jacobian of the horizontal wind. Now, the Jacobian can be rewritten as

$J(u, v)=\frac{1}{4}\left(D^{2}+\zeta^{2}\right)-\lambda^{2}$,

where $\lambda$ is the deviatoric horizontal strain rate, i.e. $\lambda$ and $-\lambda$ are eigenvalues of the deviatoric strain tensor $S$ :

$S \equiv\left(\begin{array}{ll}a & b \\ b & -a\end{array}\right)$,

where $a \equiv \frac{1}{2}\left(u_{x}-v_{y}\right), b \equiv \frac{1}{2}\left(v_{x}+u_{y}\right) . S$ measures the deformation of the flow field less the effect of horizontal divergence. Moreover, by the continuity equation, $-\partial \omega / \partial p=D$, the second and third terms in the right-hand side of Eq. (B3) can be rewritten as

$$
\begin{aligned}
& -\omega \frac{\partial D}{\partial p}-\nabla_{\mathrm{p}} \omega \cdot \frac{\partial\left(\boldsymbol{V}_{\mathrm{H}}-\boldsymbol{V}_{\mathrm{C}}\right)}{\partial p}=-\omega \frac{\partial D}{\partial p}+\omega \nabla_{\mathrm{p}} \cdot \frac{\partial\left(\boldsymbol{V}_{\mathrm{H}}-\boldsymbol{V}_{\mathrm{C}}\right)}{\partial p} \\
& -\nabla_{\mathrm{p}} \cdot\left[\omega \frac{\partial\left(\boldsymbol{V}_{\mathrm{H}}-\boldsymbol{V}_{\mathrm{C}}\right)}{\partial p}\right]=\nabla_{\mathrm{p}} \cdot\left\{-\frac{\partial}{\partial p}\left[\omega\left(\boldsymbol{V}_{\mathrm{H}}-\boldsymbol{V}_{\mathrm{C}}\right)\right]\right\} \\
& -\left(\boldsymbol{V}_{\mathrm{H}}-\boldsymbol{V}_{\mathrm{C}}\right) \cdot \nabla_{\mathrm{p}} D-D^{2} .
\end{aligned}
$$

Combining Eqs. (B4) and (B5) and using $\zeta_{\mathrm{a}} \equiv f+\zeta$, the tendency equation for horizontal divergence can be derived as in Eq. (2). 